\title{
GHzürich
}

\section{Research Collection}

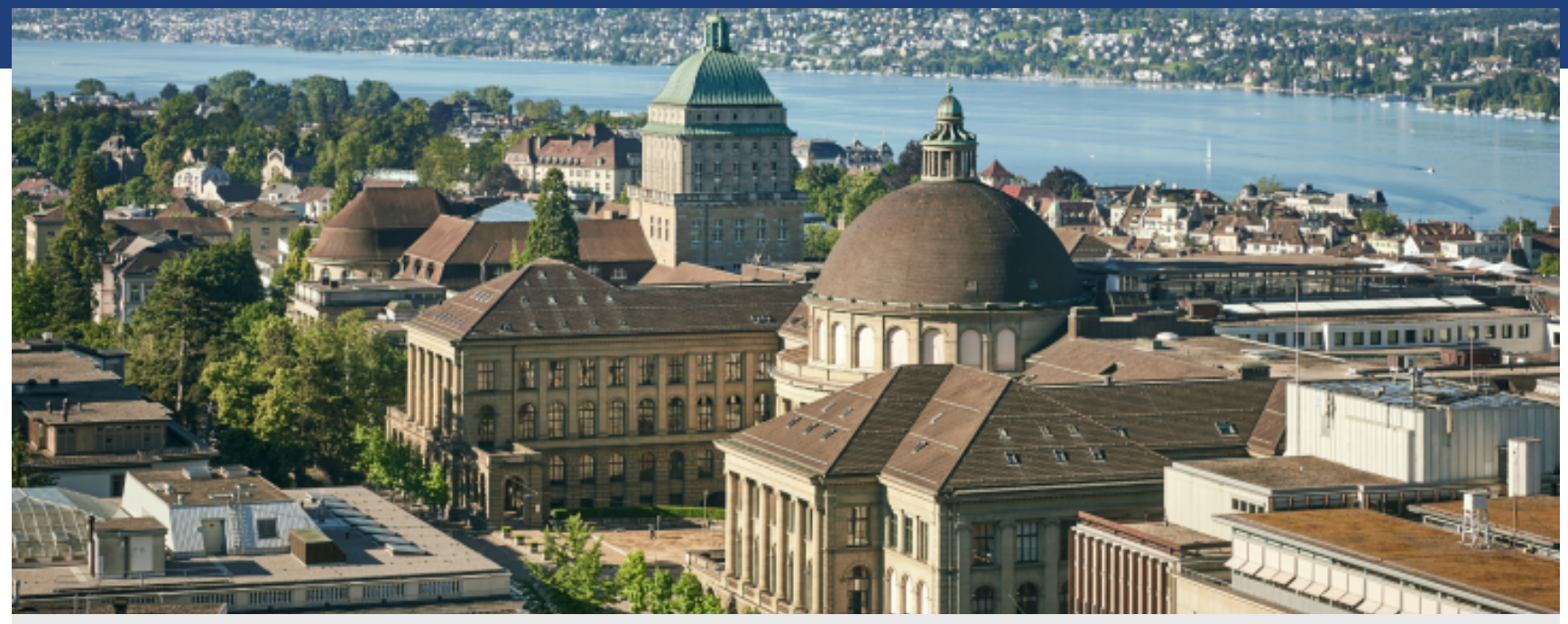

Working Paper

\section{MOBIS-COVID19/25 \\ Results as of 19/10/2020 (post-lockdown)}

\section{Author(s):}

Molloy, Joseph; Tchervenkov, Christopher; Schatzmann, Thomas; Schoeman, Beaumont; Hintermann, Beat; Axhausen, Kay W.

\section{Publication Date:}

2020-10

\section{Permanent Link:}

https://doi.org/10.3929/ethz-b-000447684 $\rightarrow$

\section{Rights / License:}

Creative Commons Attribution-NonCommercial-ShareAlike 4.0 International $\rightarrow$ 


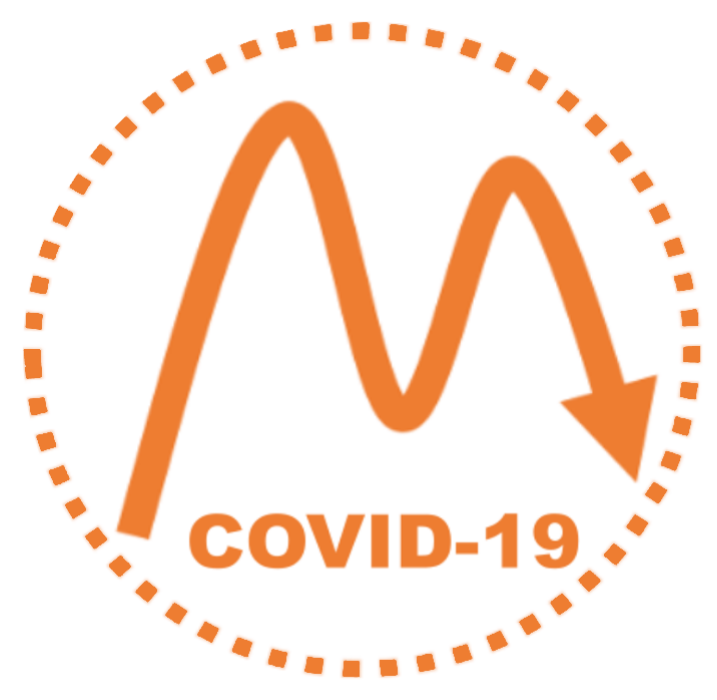

\section{MOBIS-COVID19/25}

Results as of 19/10/2020 (post-lockdown)

Joseph Molloy

Christopher Tchervenkov

Thomas Schatzmann

Beaumont Schoeman

Beat Hintermann

Kay W. Axhausen

\section{EIH}

$\square \square \sqrt{2 \text { Institut für Verkehrsplanung und Transportsysteme }}$

Eidgenössische Technische Hochschule Zürich Swiss Federal Institute of Technology Zurich 


\title{
MOBIS-COVID19/25
}

\author{
Joseph Molloy \\ Christopher Tchervenkov \\ IVT \\ ETH Zurich \\ CH-8093 Zurich \\ IVT \\ ETH Zurich \\ CH-8093 Zurich \\ joseph.molloy@ivt.baug.ethz.ch \\ christopher.tchervenkov@ivt. baug. ethz.ch \\ Thomas Schatzmann \\ Beaumont Schoeman \\ IVT \\ WWZ \\ ETH Zurich \\ University of Basel \\ CH-8093 Zurich \\ CH-4002 Basel \\ thomas.schatzmann@ivt.baug.ethz.ch \\ b.schoeman@unibas.ch \\ Beat Hintermann \\ Kay W. Axhausen \\ WWZ \\ IVT \\ University of Basel \\ ETH Zurich \\ CH-8093 Zurich \\ CH-4002 Basel \\ axhausen@ivt.baug.ethz.ch
}

October 2020

\section{Abstract}

To slow down the spread of the Coronavirus, the population has been instructed to stay at home if possible. This measure consequently has a major impact on our daily mobility behaviour. But who is being affected, and how? The MOBIS-COVID-19 research project, an initiative of ETH Zurich and the University of Basel, is a continuation of the original MOBIS study. The aim of the project is to get a picture of how the crisis is affecting mobility and everyday life in Switzerland.

\section{Keywords}

GPS logger; Travel diary app; COVID-19; Corona virus; MOBIS; Mobility behaviour; Switzerland

\section{Suggested Citation}

Molloy, J., C. Tchervenkov, T. Schatzmann, B. Schoeman, B. Hintermann and K.W. Axhausen (2020) MOBIS-COVID19/25: Results as of 19/10/2020 (post-lockdown), Arbeitsberichte Verkehrs- und Raumplanung, 1570, IVT, ETH Zurich, Zurich. 


\title{
MOBIS-COVID19/25
}

\author{
Joseph Molloy \\ Christopher Tchervenkov \\ IVT \\ ETH Zurich \\ CH-8093 Zurich \\ IVT \\ ETH Zurich \\ CH-8093 Zurich \\ joseph.molloy@ivt.baug.ethz.ch \\ christopher.tchervenkov@ivt. baug. ethz.ch \\ Thomas Schatzmann \\ Beaumont Schoeman \\ IVT \\ WWZ \\ ETH Zurich \\ University of Basel \\ CH-8093 Zurich \\ CH-4002 Basel \\ thomas.schatzmann@ivt.baug.ethz.ch \\ b.schoeman@unibas.ch \\ Beat Hintermann \\ Kay W. Axhausen \\ WWZ \\ IVT \\ University of Basel \\ ETH Zurich \\ CH-8093 Zurich \\ CH-4002 Basel \\ axhausen@ivt.baug.ethz.ch
}

Oktober 2020

\section{Zusammenfassung}

Um die Ausbreitung des Coronavirus zu verlangsamen ist die Bevölkerung angewiesen worden, wenn möglich zu Hause zu bleiben. Diese Massnahme hat daher einen grossen Einfluss auf unser tägliches Mobilitätsverhalten. Doch wer ist davon betroffen und wie? Das Forschungsprojekt MOBIS-COVID-19, eine Initiative der ETH Zürich und der Universität Basel, ist eine Weiterführung der originalen MOBIS-Studie. Ziel des Projekts ist es, ein Bild zu erhalten, wie sich die Krise auf die Mobilität und das Alltagsleben in der Schweiz auswirkt.

\section{Schlagworte}

GPS logger; Travel diary app; COVID-19; Corona virus; MOBIS; Mobility behaviour; Switzerland

\section{Zitierungsvorschlag}

Molloy, J., C. Tchervenkov, T. Schatzmann, B. Schoeman, B. Hintermann and K.W. Axhausen (2020) MOBIS-COVID19/25: Results as of 19/10/2020 (post-lockdown), Arbeitsberichte Verkehrs- und Raumplanung, 1570, IVT, ETH Zurich, Zurich. 


\section{Contents}

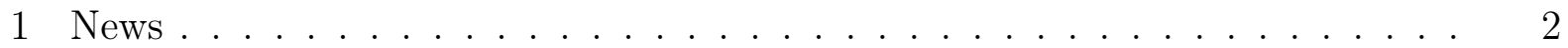

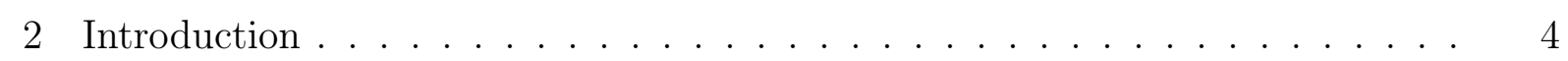

3 Average daily distance $\ldots \ldots \ldots \ldots \ldots$

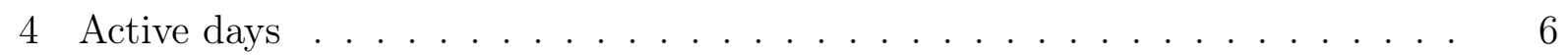

5 Change in kilometers travelled by transport mode . . . . . . . . . . . . . . . . 6

6 Key indicators by mode $\ldots \ldots \ldots \ldots \ldots$. . . . . . . . . . . . . . 7

7 Change in kilometers travelled by: . . . . . . . . . . . . . . . . . . . . . . 7

8 Analysis of trip purpose $\ldots \ldots \ldots \ldots \ldots$

9 Road travel speeds . . . . . . . . . . . . . . . . . . . . . . . 14

10 Shifts in the transport mode share . . . . . . . . . . . . . . . . . . . 14

11 Reduction in kilometers travelled by working arrangement . . . . . . . . . . . 16

12 Reduction in kilometers travelled by Canton . . . . . . . . . . . . . . . . . . . 18

13 Trip duration by transport mode and gender . . . . . . . . . . . . . . . 18

14 Average stage length by transport mode $(\mathrm{km})$

15 Activity space and daily travel radius . . . . . . . . . . . . . . . . . . . . . . . 19

16 Hourly counts . . . . . . . . . . . . . . . . . . . . . . . . . 21

17 Activity types and zoning . . . . . . . . . . . . . . . . . . . . . . 24

18 Participation . . . . . . . . . . . . . . . . . . . . 25

19 Risk perception . . . . . . . . . . . . . . . . . . . . . . . . . . 25

20 Differences in the distributions . . . . . . . . . . . . . . . . . . . . . 26

21 Sample weighting . . . . . . . . . . . . . . . . . . . . . . . . . . . . . . 28

22 Updated conclusions $\ldots \ldots \ldots \ldots \ldots \ldots$ 


\section{News}

5 October:

- The chart showing the daily average distance by gender has been corrected to show total distance, whereas it previously included only car travel. Also the same graph now displays a 4 day rolling average for visibility. The original values are still available in the downloadable data.

28 September:

- New chart with key transport-mode indicators added.

24 August:

- Updated conclusions.

- The report will now be updated every second week.

11 August:

- New analysis of trip purpose (mode shares and hourly counts).

- Weekly weights of the sample against the original MOBIS study have been applied to all results.

6 August:

- Added breakdown of the current sample to the section 'Differences in the distributions'.

13 July:

- As of July 6th, face masks are compulsory on public transport in Switzerland.

- To reflect this development, the relevant graphs have vertical lines added indicating the start of the lockdown (March 16th), relaxation of the lockdown (May 11th) and the introduction of the mask requirement (July 6th). 
29 June:

- New analysis on the shifts in the transport mode share.

15 June:

- The data can now be downloaded directly for certain requested charts. Please make sure to cite both the IVT, ETHZ and WWZ, Uni Basel as the source.

- Hourly counts now show the whole day - Midnight to 4am is no longer excluded.

- Analysis by home office

- In response to multiple inquiries, we would like to clarify that the baseline-2019 period covers September and October 2019.

- Results by gender corrected

- New analysis of car travel speeds by distance class

25 May:

- Adjusted \#Activities/Day so that the first home activity per day is not included.

- Converted long tables to graphs.

18 May:

- First report after the relaxation of lockdown measures on May 11th.

- The 2019 Baseline period has been shortened to only include September and October, this mostly affects the cycling numbers.

11 May:

- New graph of activity space and daily radius.

4 May:

- New chart from online survey with participants on risk perception.

- Key points summary and formatting adjustments.

27 April:

- New chart on the change in activity type by land zoning. 
20 April:

- Mobile participants per day.

- Non-mobile participants are now included in the activity-space numbers in addition to a new table on median weekly activity spaces.

- New graphs, including average trip distance by mode.

- Formatting improvements and other small corrections.

13 April:

- Earlier weeks have been grouped and colored grey in certain graphs.

\section{Introduction}

On March 16, 2020, 3700 participants who completed the MOBIS study between September 2019 and January 2020 were invited to reinstall the GPS Logger and Travel Diary App 'Catch-My-Day', developed by MotionTag, to record their mobility behaviour during the period of special measures implemented to control the spread of the Corona Virus. The first 4 weeks of mobility data from the original MOBIS Study is taken for each participant as a baseline against which to compare current mobility patterns. These 4 weeks start place anywhere between 1st September and 15th November, depending on the participant. Only trips in Switzerland are currently considered, although data on cross border travel is available.

A running panel of around 250 participants were already tracking before the sample was reinvited. This allows results for the weeks before the MOBIS:COVID-19 study was officially started, although the sample size is a lot smaller, and hence the results.

In the MOBIS study, participants were only eligible if they used a car at least 3 days a week - which skews the sample away from the Swiss general population.

The number of tracking participants each day used to calculate the average daily values includes all participants who recorded tracks before or after that date. This allows the consideration of those who stay at home while still allowing for survey dropouts. 
The GPS Travel diary used, Catch-My-Day (for iOS and Android) can have a 2-3 day delay before the tracks are available for analysis. The scaling by active participants accommodates for this, but the results of previous reports may change when the report is updated.

\section{Average daily distance}

\section{Average daily $\mathrm{km}$ travelled by gender}

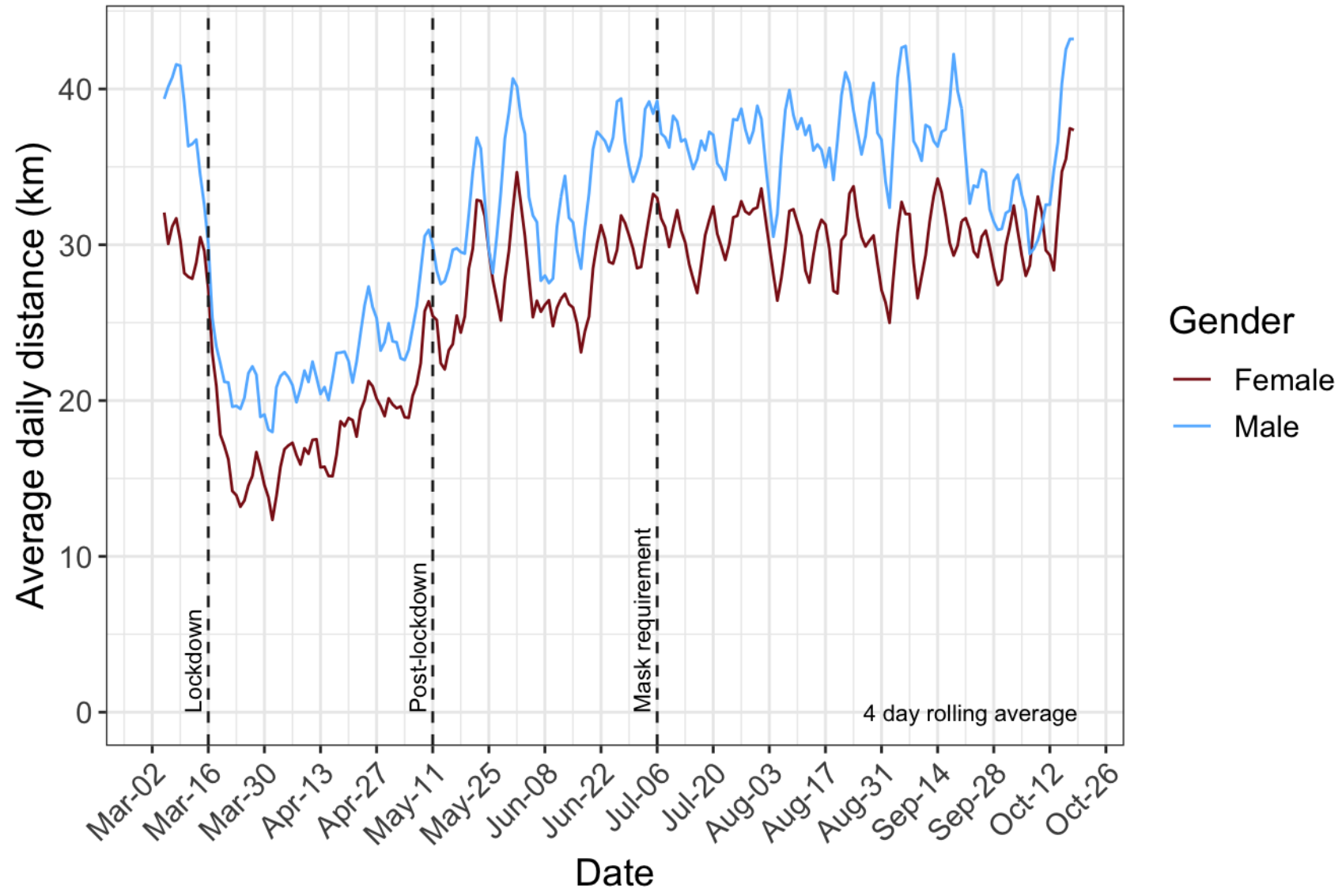




\section{$4 \quad$ Active days}

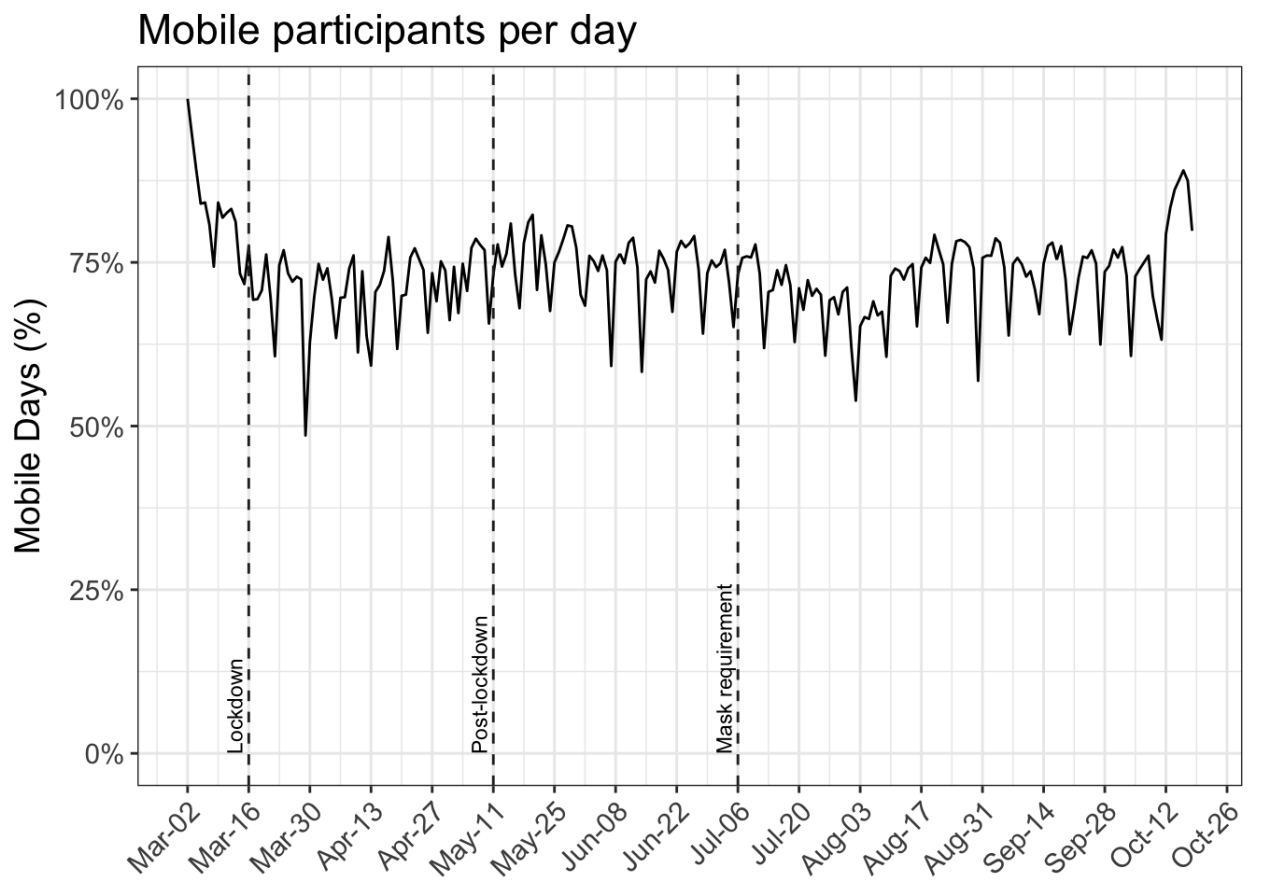

\section{Change in kilometers travelled by transport mode}

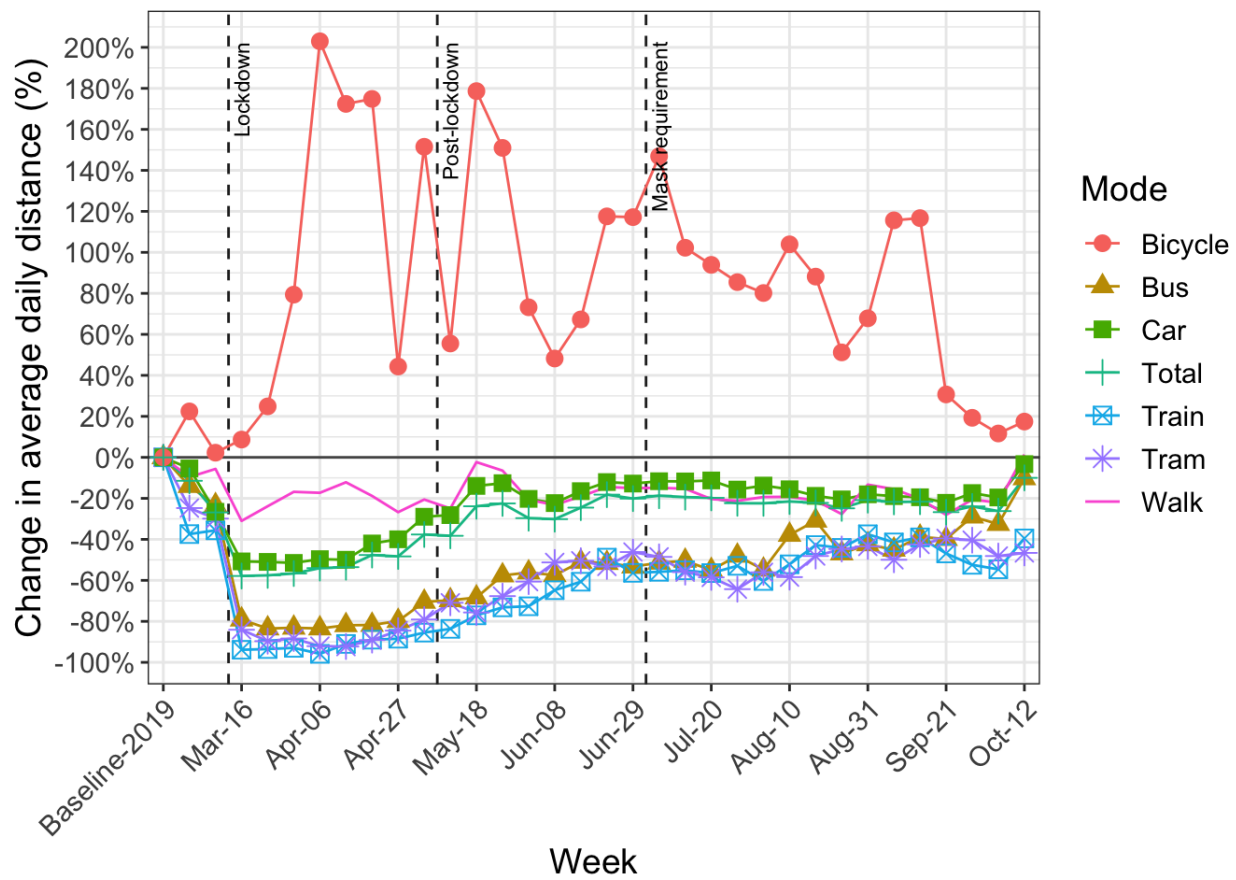




\section{Key indicators by mode}

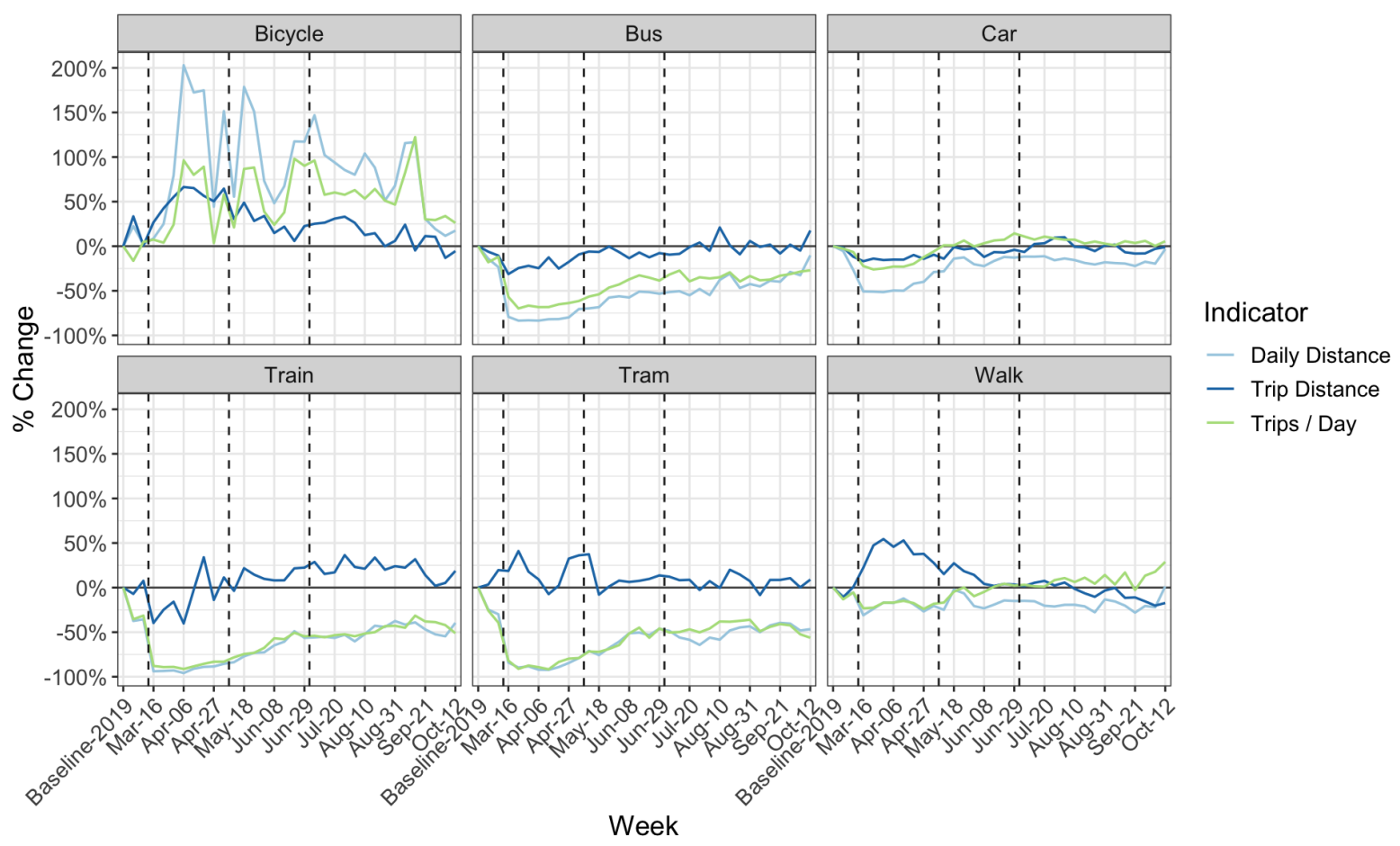

\section{Change in kilometers travelled by:}
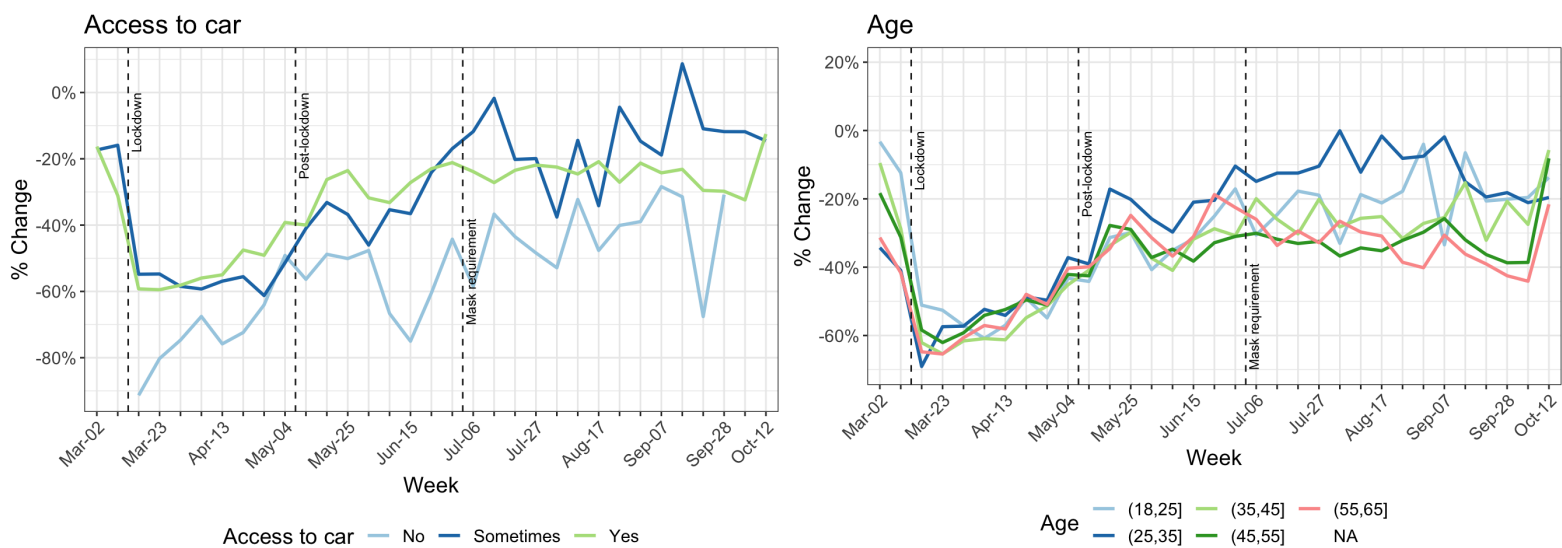


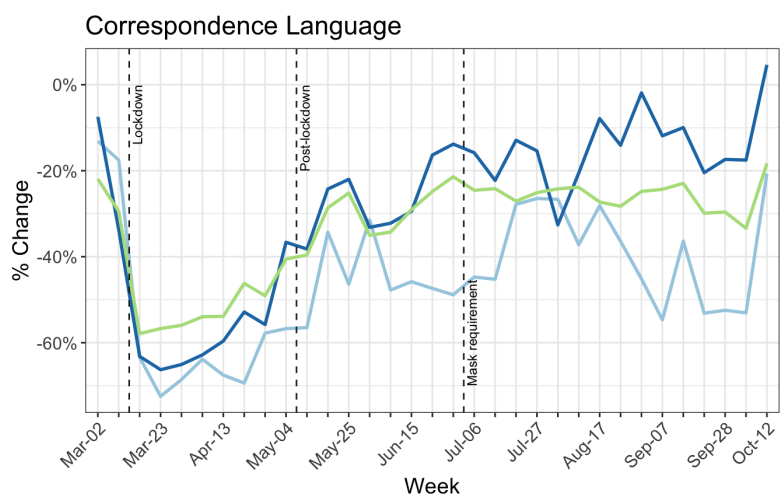

Correspondence Language - English - French - German
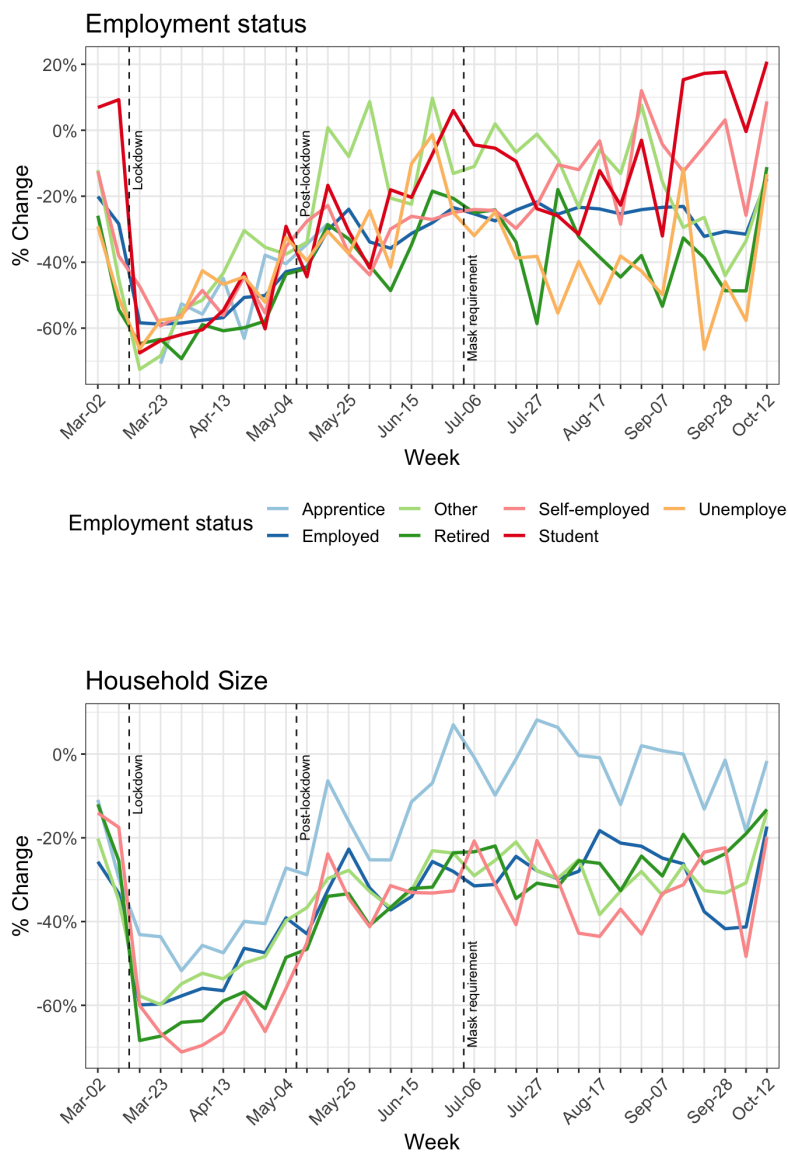

Household Size $-1-2-3-4-5$ or more

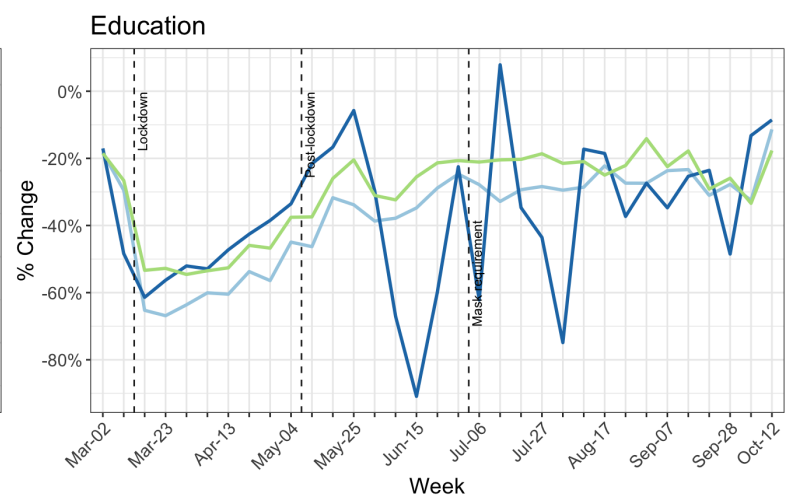

Education - Higher - Mandatory - Secondary
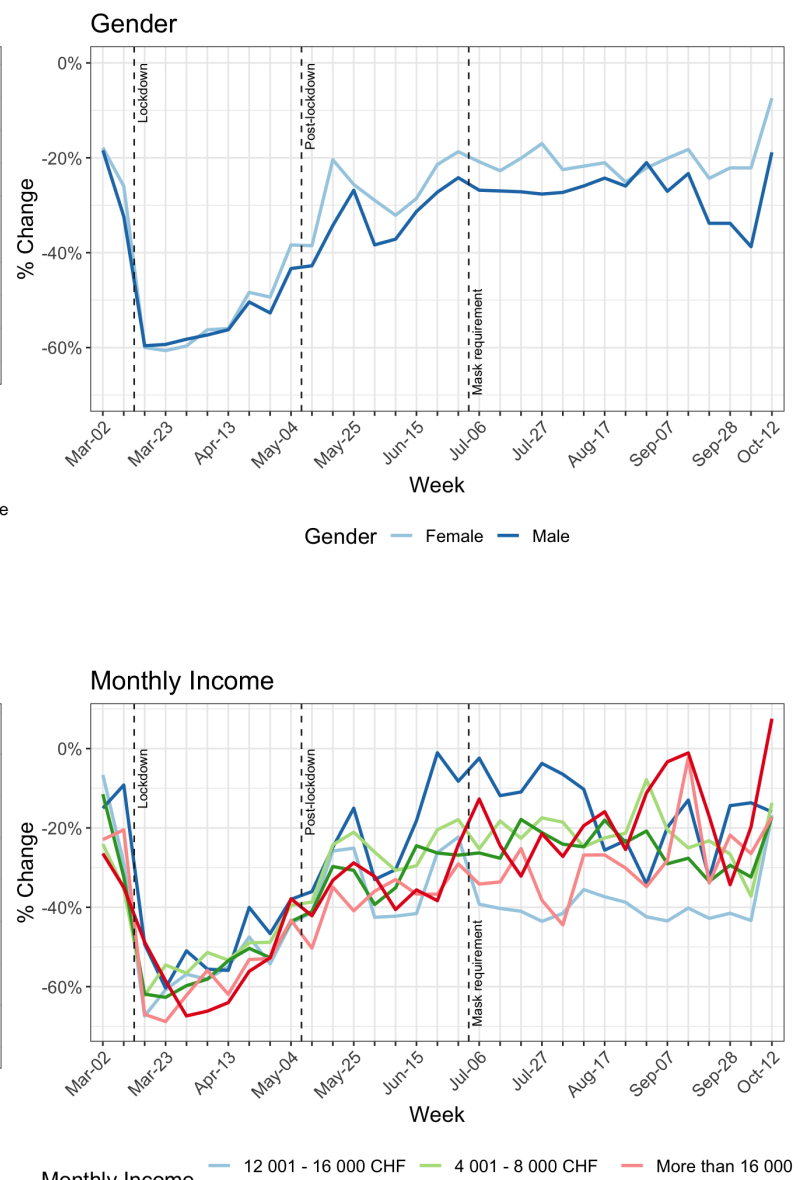

Monthly Income $-12001-16000 \mathrm{CHF}-4001-8000 \mathrm{CHF}-$ More than 16000
$-4000 \mathrm{CHF}$ or less $-8001-12000 \mathrm{CHF}-$ Prefer not to say 


\section{$8 \quad$ Analysis of trip purpose}
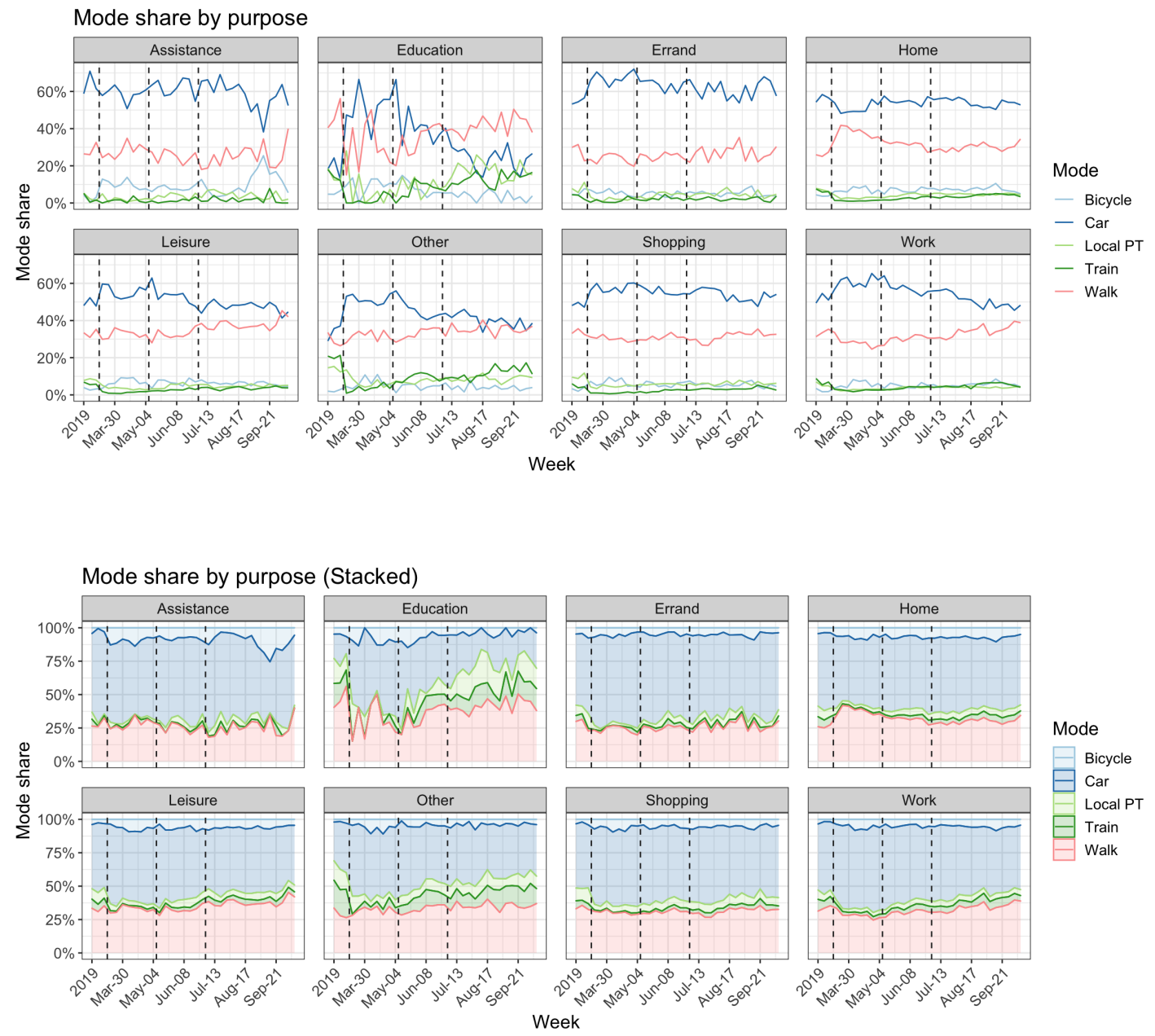
Average trip length by purpose

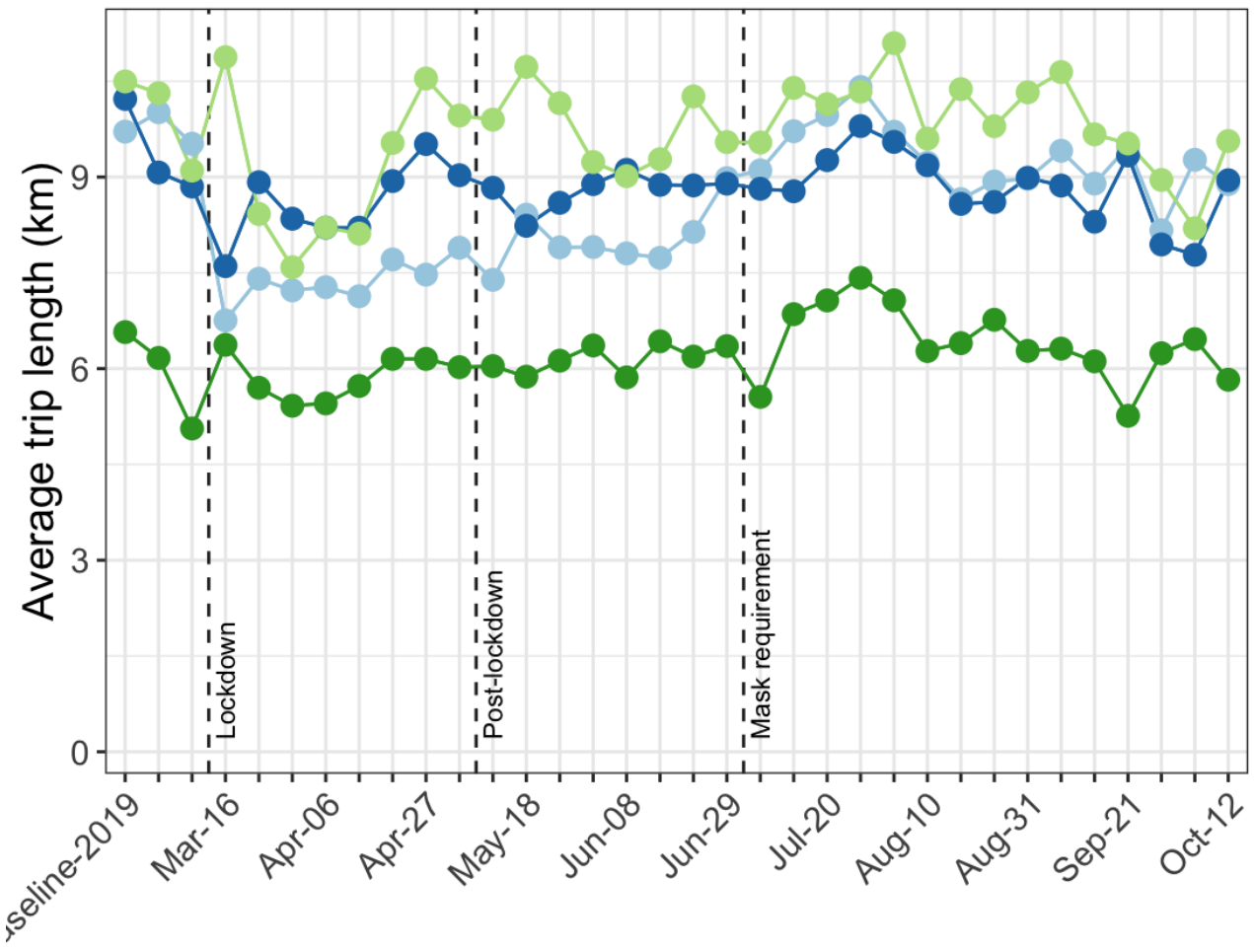

Week

Change in cycling mode share by purpose

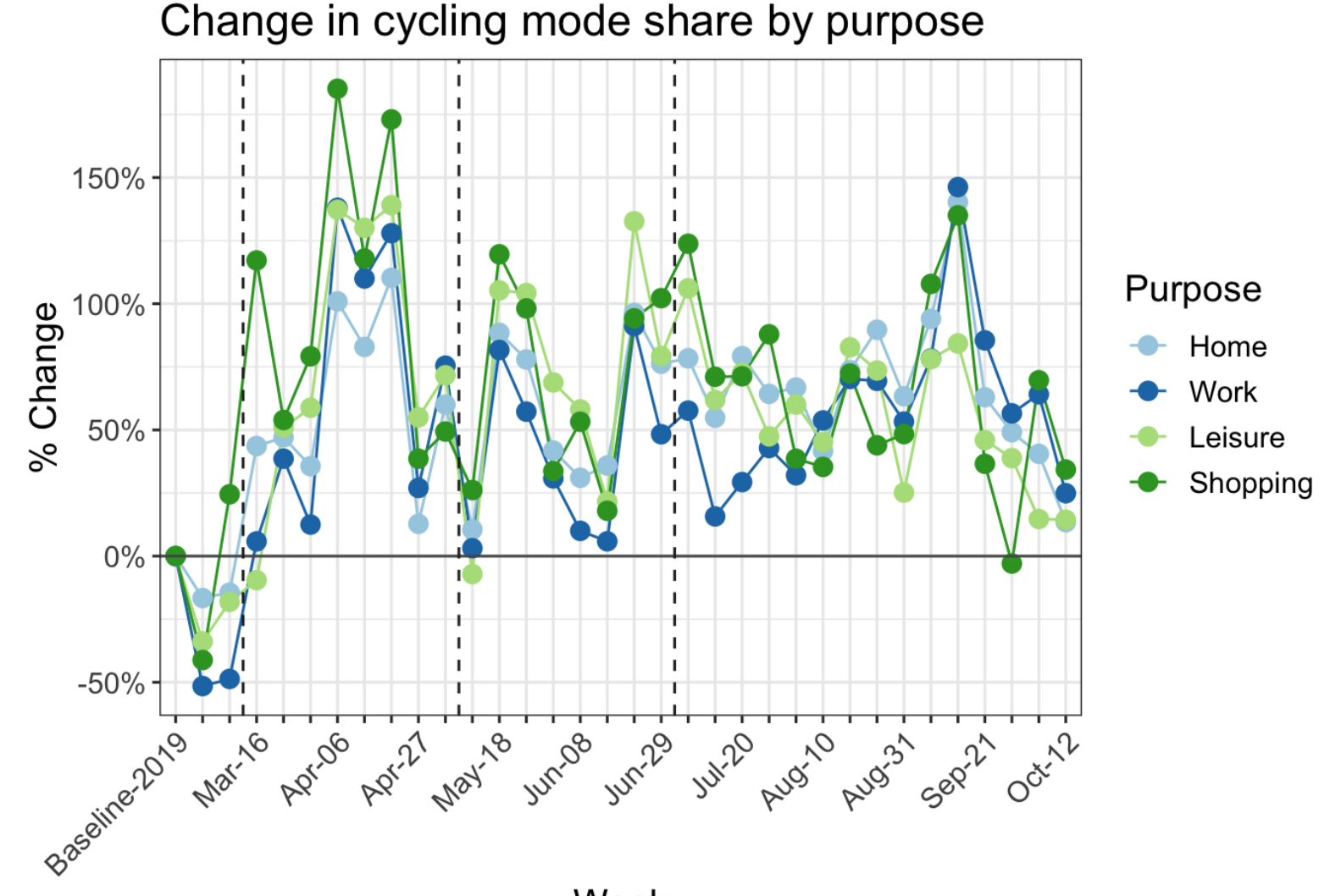

Week

\section{Purpose}

- - Home

- Work

- Leisure

- Shopping

Week 

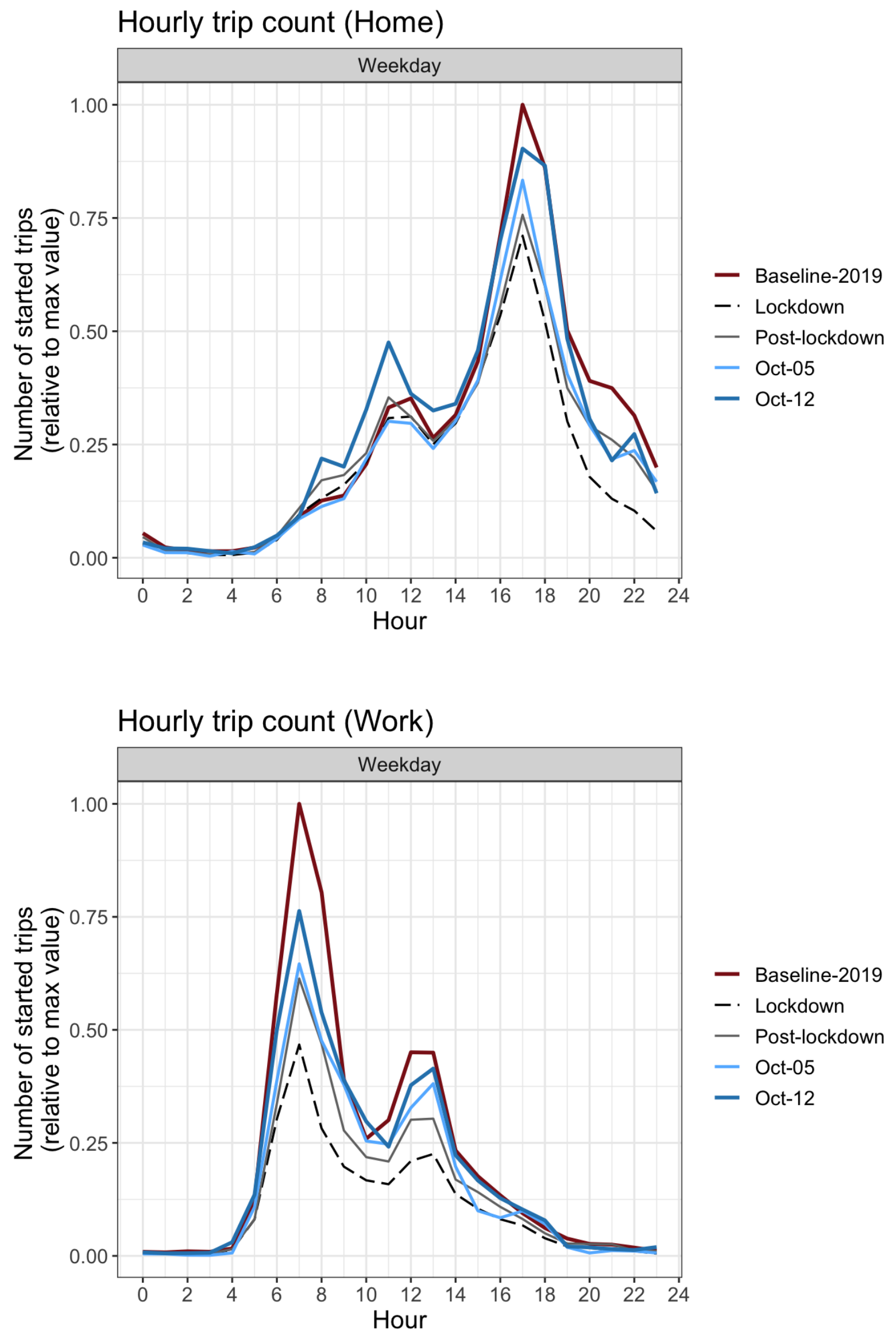


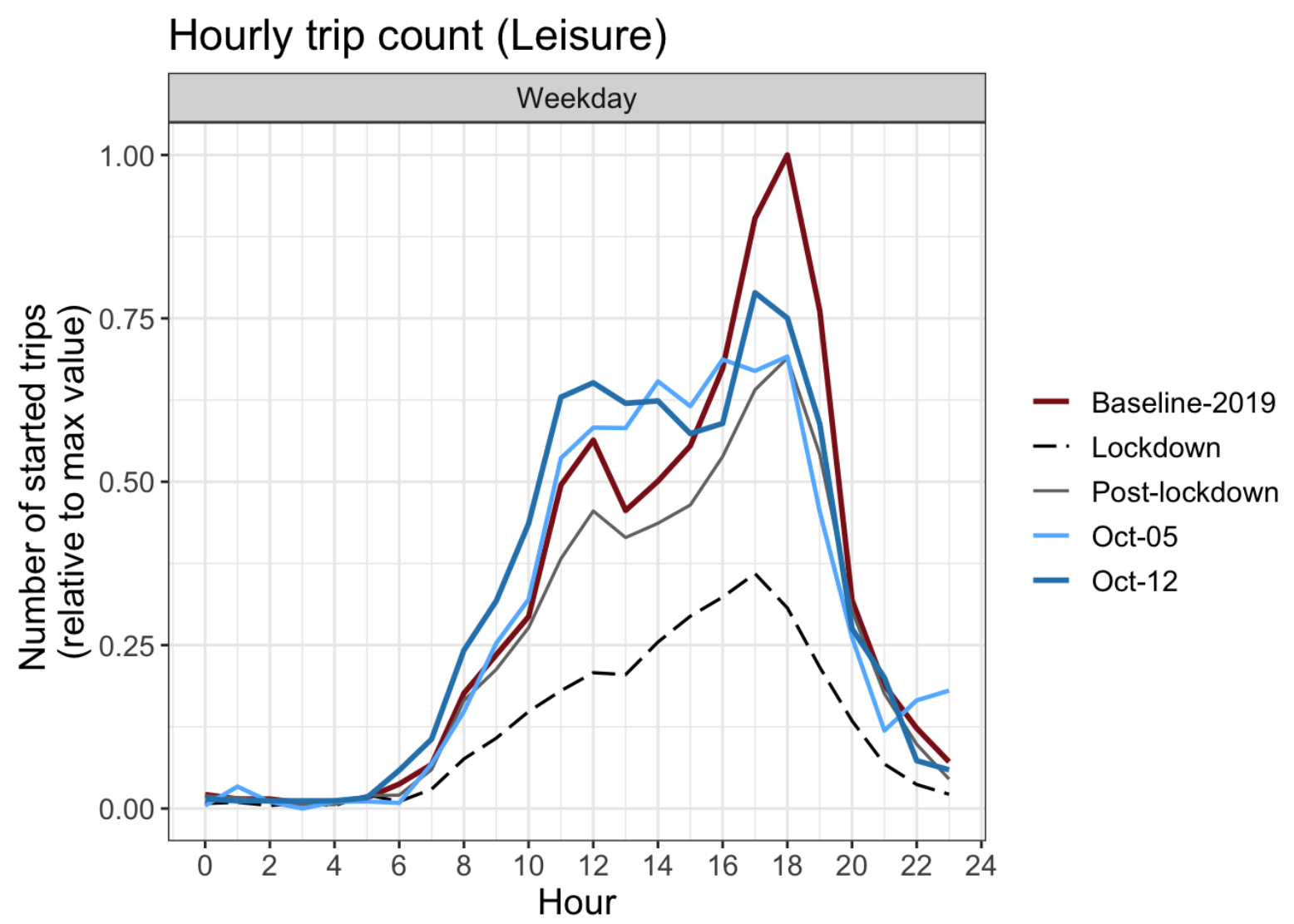

Hourly trip count (Shopping)

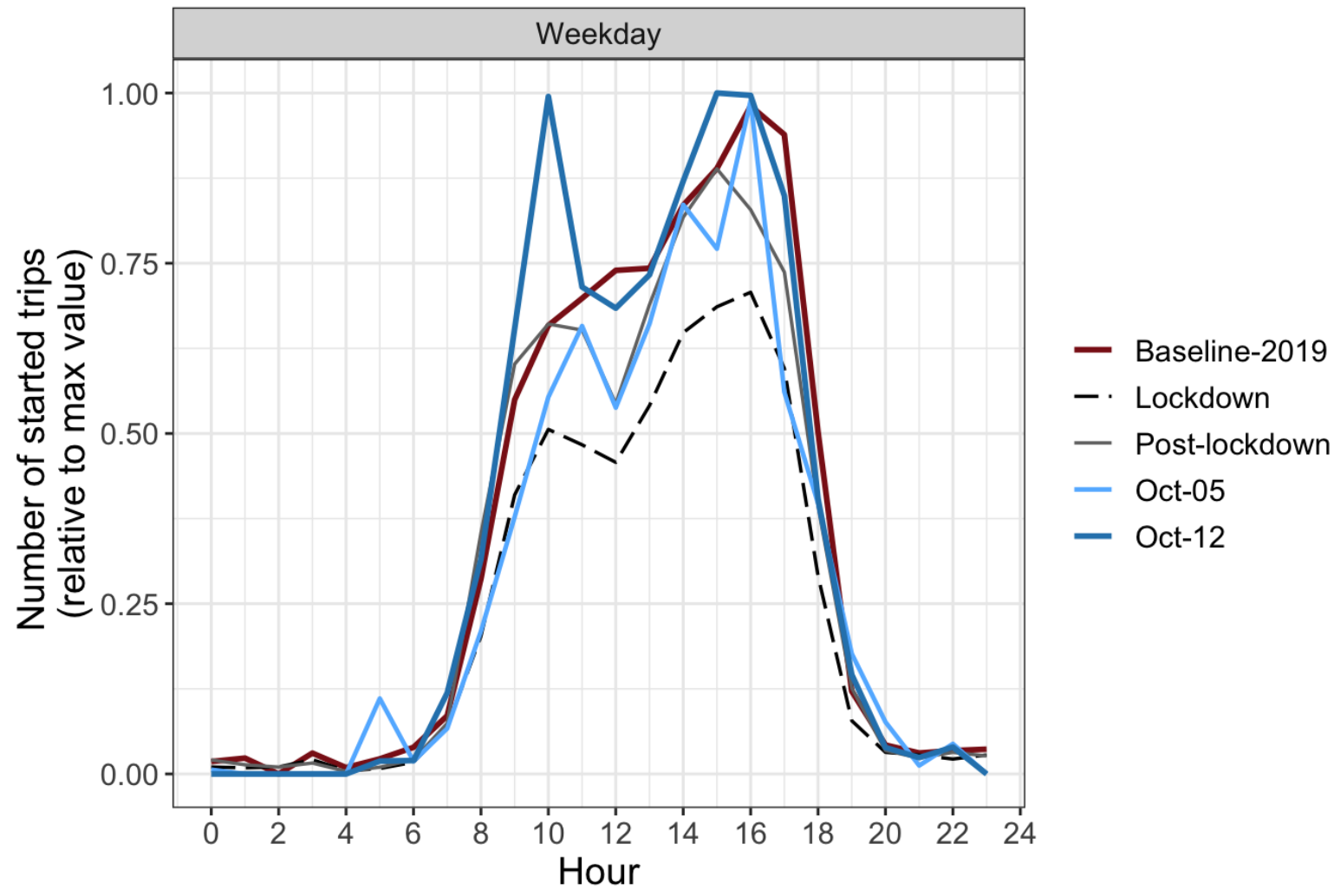




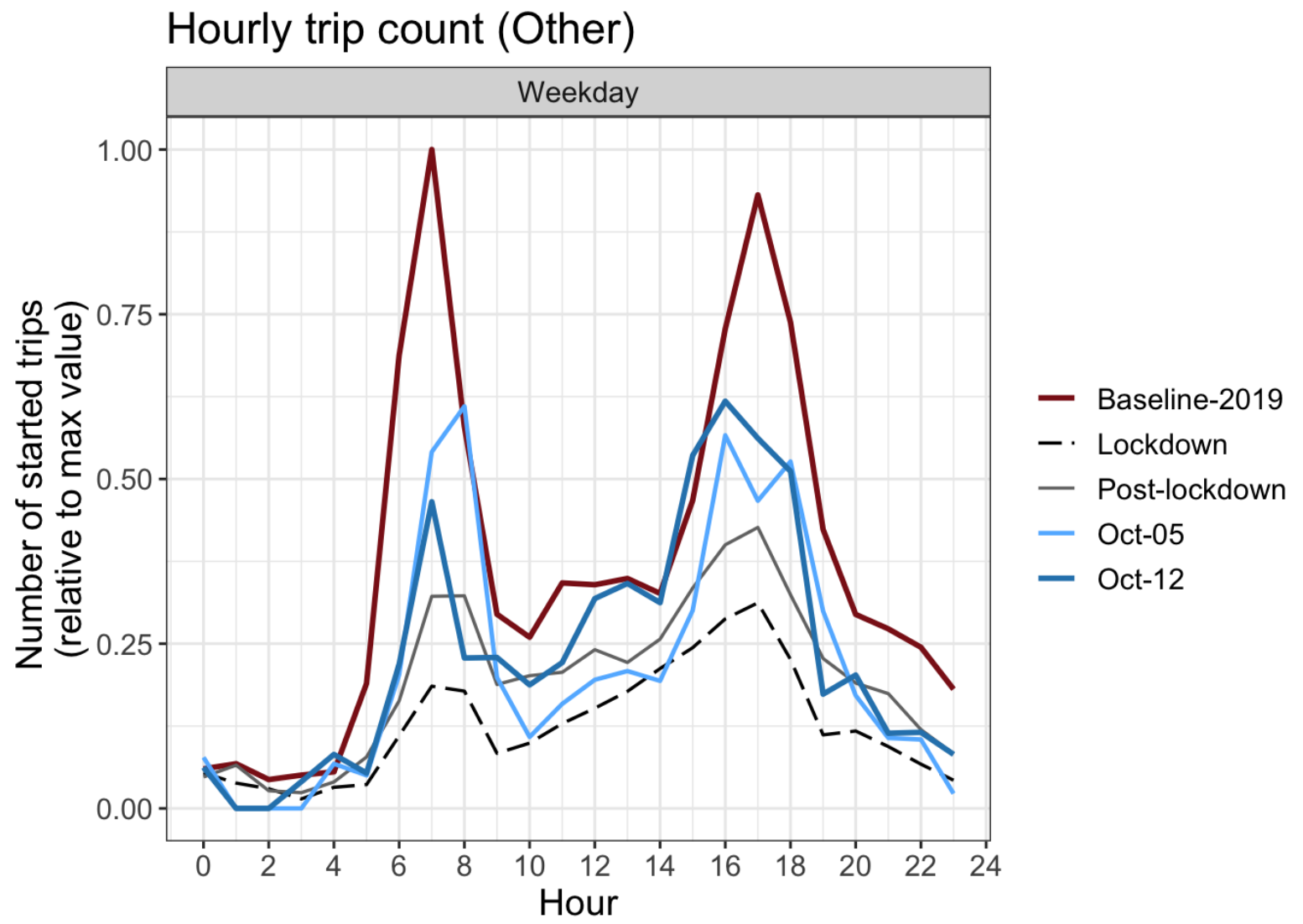

Hourly trip count (Education)

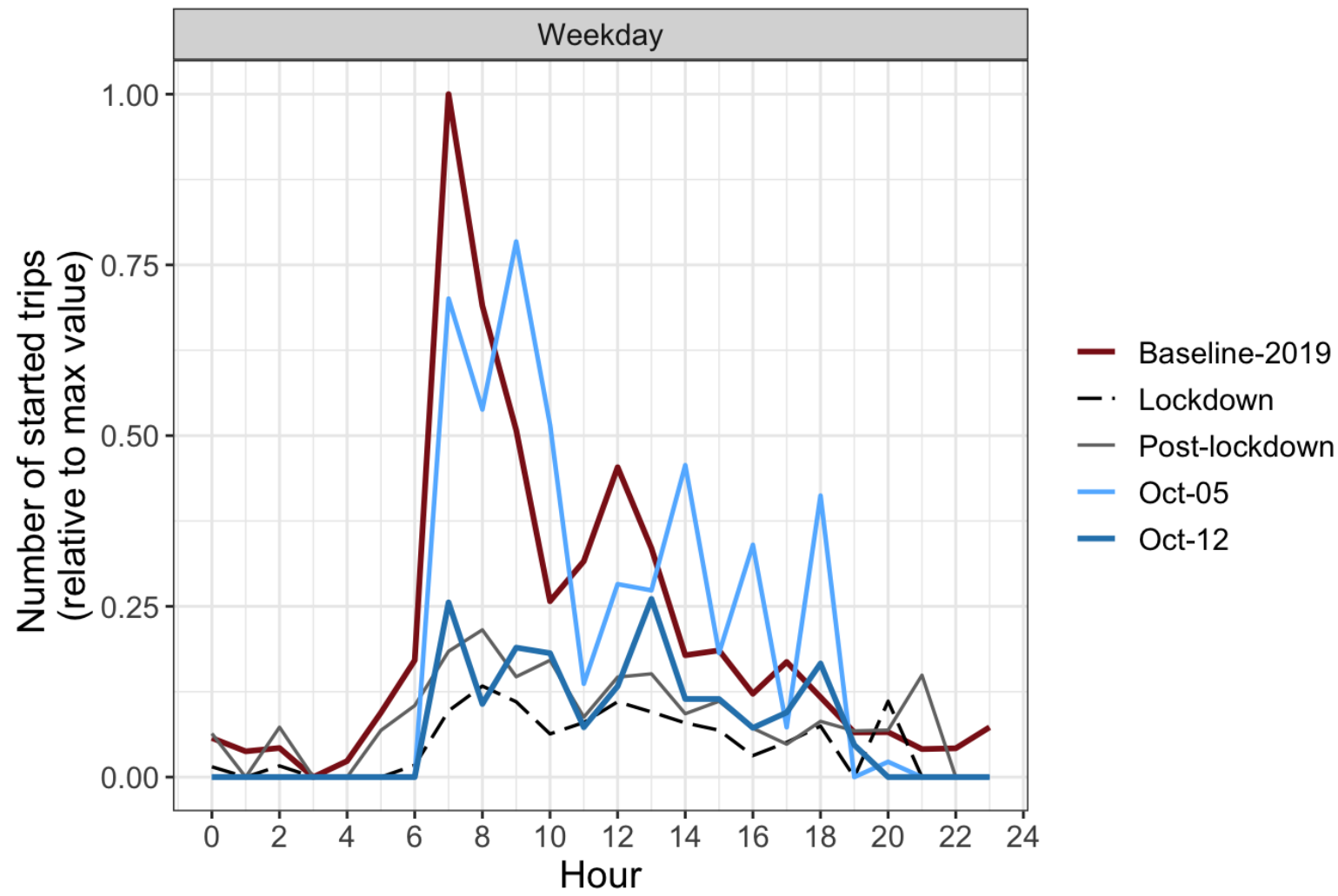




\section{$9 \quad$ Road travel speeds}

The following graph shows the effect of the COVID-19 crisis on median car travel speeds during the week, i.e. excluding weekends and holidays. During the lockdown period from March 16th to May 11th, an increase in the peak-hour speeds was observed, indicating a decrease in overall congestion. Since the relaxation of the measures, peak-hour speeds have returned to pre-COVID-19 values, a sign that congestion is back to usual levels.

The effect of the COVID-19 crisis

on travel speeds

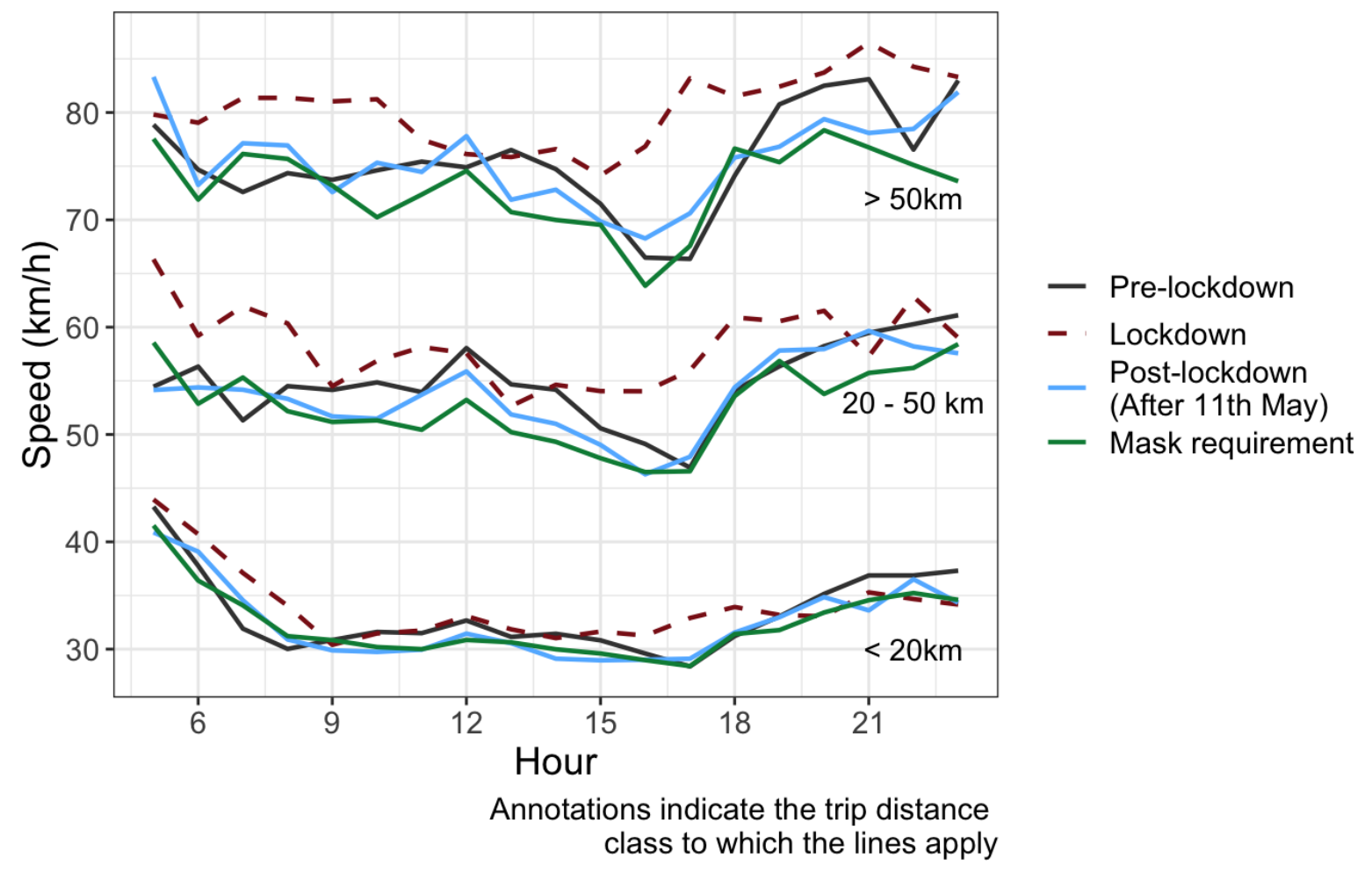

\section{Shifts in the transport mode share}

A ternary plot is the graphical representation of triplets of numerical data. It is suitable for representing a constant sum, which is broken down into three summands. The following figure shows an example of such a plot with a single point. The triplet corresponding to this point can be read by following the green lines: $\mathrm{A}=0.5, \mathrm{~B}=0.3$ and $\mathrm{C}=0.2$. The sum of the three values is equal to 1 . 


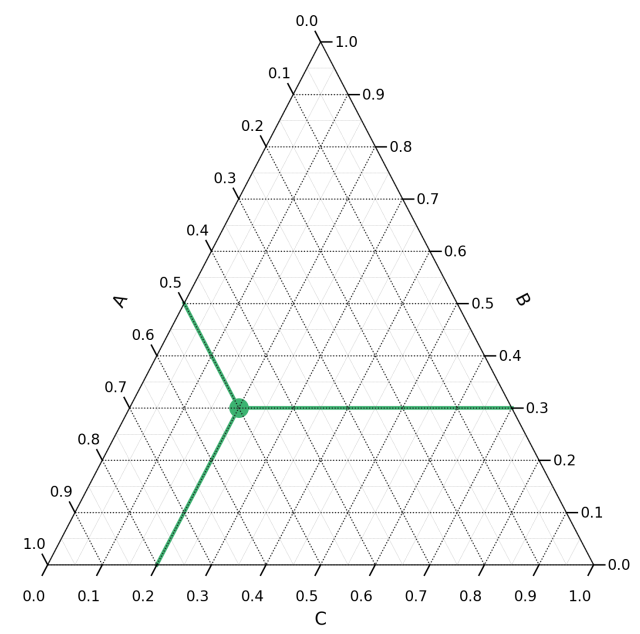

The following ternary plots show the change in mode shares over the course of the COVID19 crisis, for different types of public transport subscriptions (GA, Halbtax and other). The modes are grouped into the following categories:

- Motorized individual transport (car, motorbike, taxi, Uber)

- Public transport (bus, tram, ferry, metro, train)

- Unmotorized transport (walk, bike)

During the lockdown, a higher share of kilometers and trips were performed using motorized individual and unmotorized modes as compared to the reference period. After the lockdown, the share of public transport has increased and the share unmotorized modes has decreased, both slightly. The share of motorized individual modes it still greater than during the reference period.

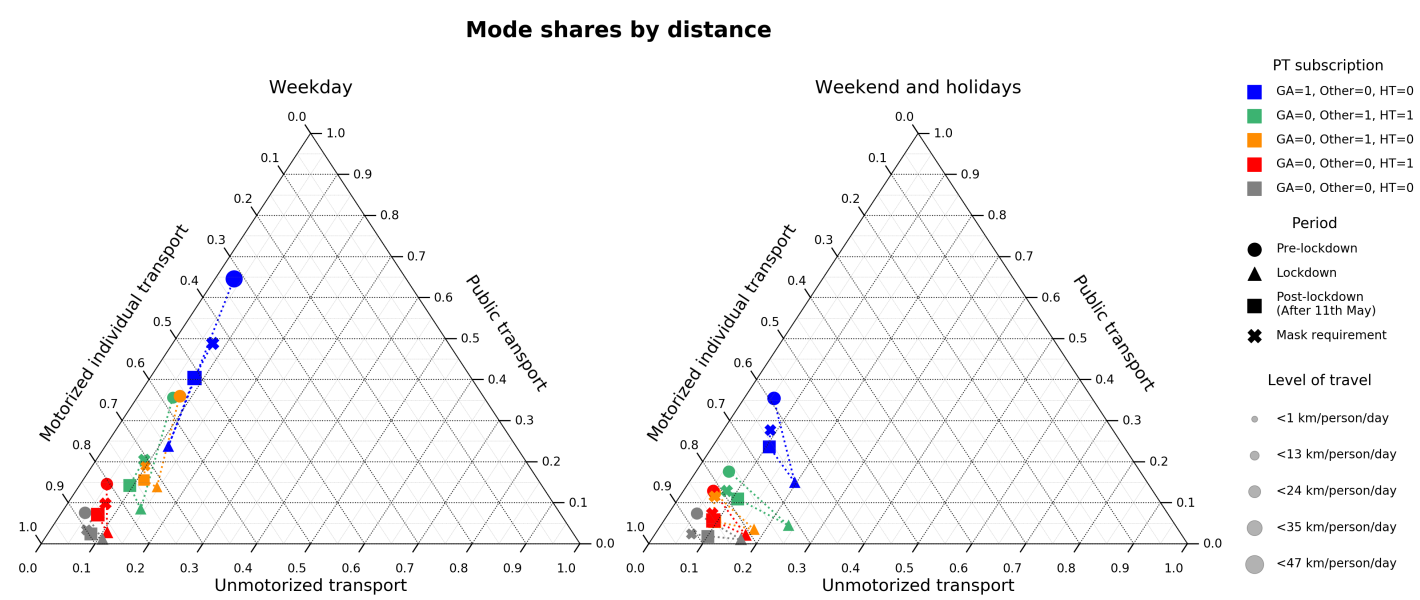




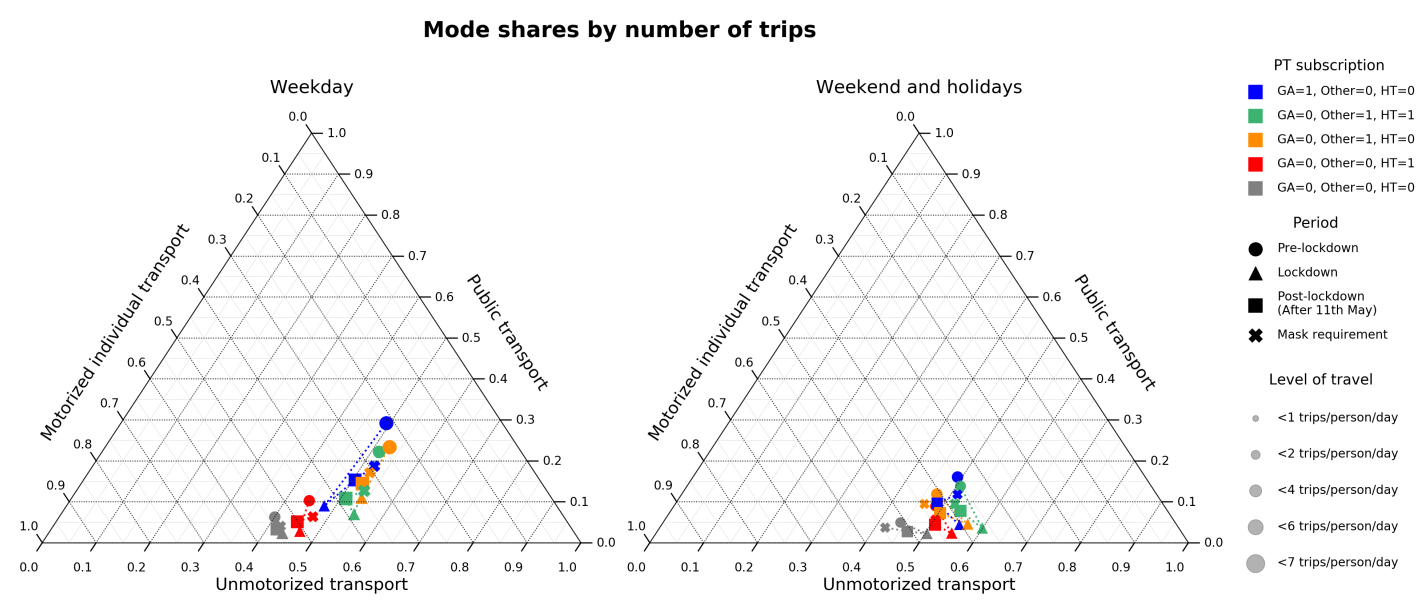

\section{Reduction in kilometers travelled by working arrangement}

Participants in MOBIS-Covid19 were asked to report their working status on 24/4/2020. The following charts use these results, with the working status imputed using sociodemographic indicators for those who didn't respond. Specifically, we asked for the number of days working both at home and out of home, and these were then grouped into the categories used below:

- Working only at home

- Only working out of home

- A mix of home office and normal conditions

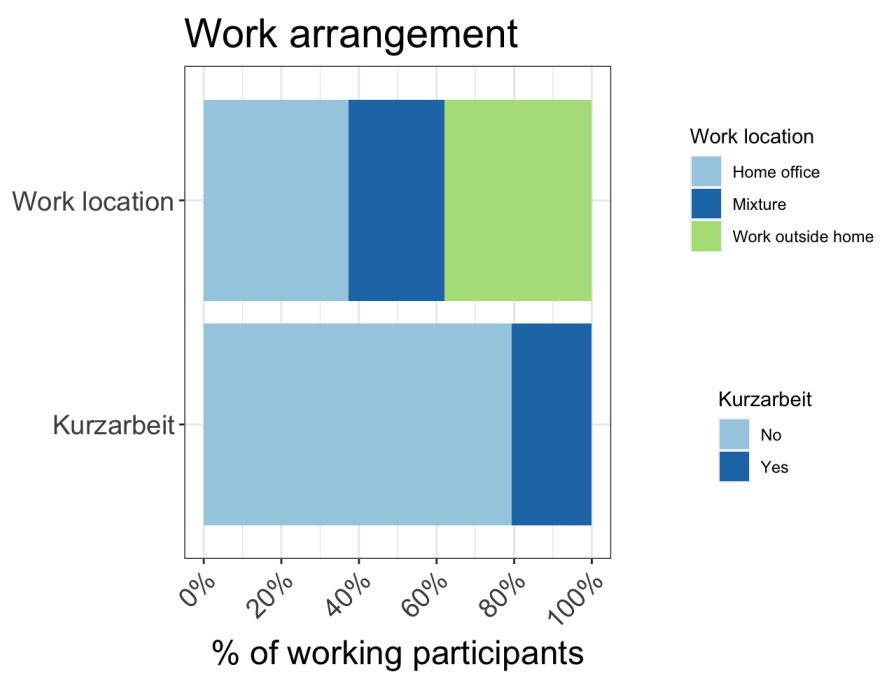




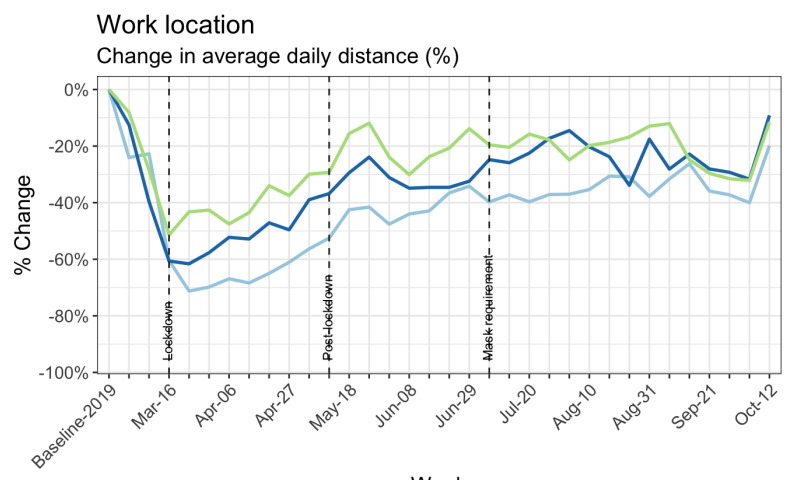

Week

- Home office - Mixture - Work outside home

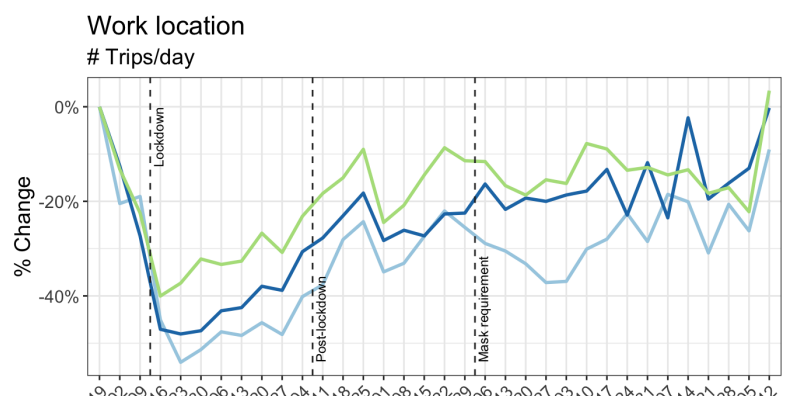

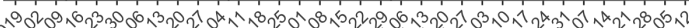
20ja ja

Week

- Home office - Mixture - Work outside home
Kurzarbeit (if in employment)

Change in average daily distance (\%)

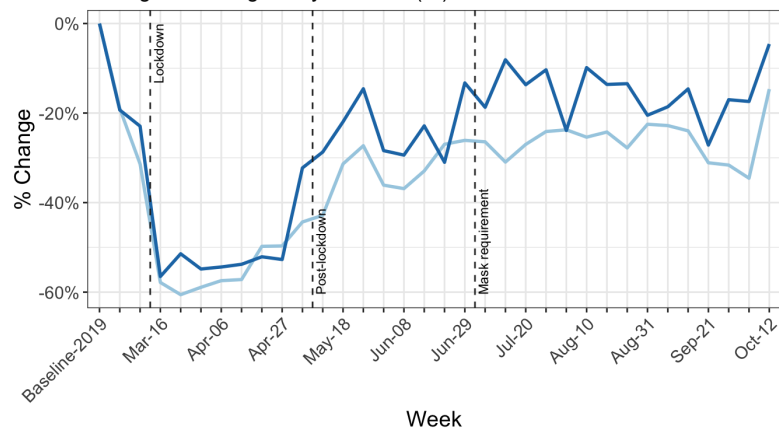

Kurzarbeit - No - Yes

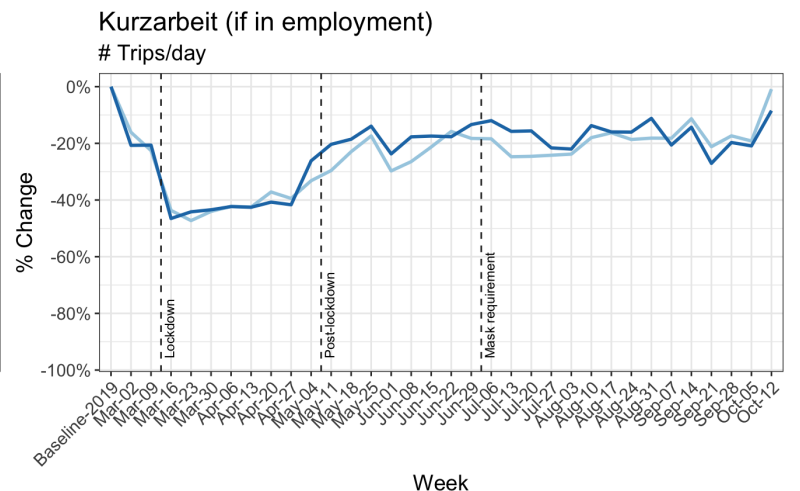

Kurzarbeit - No - Yes

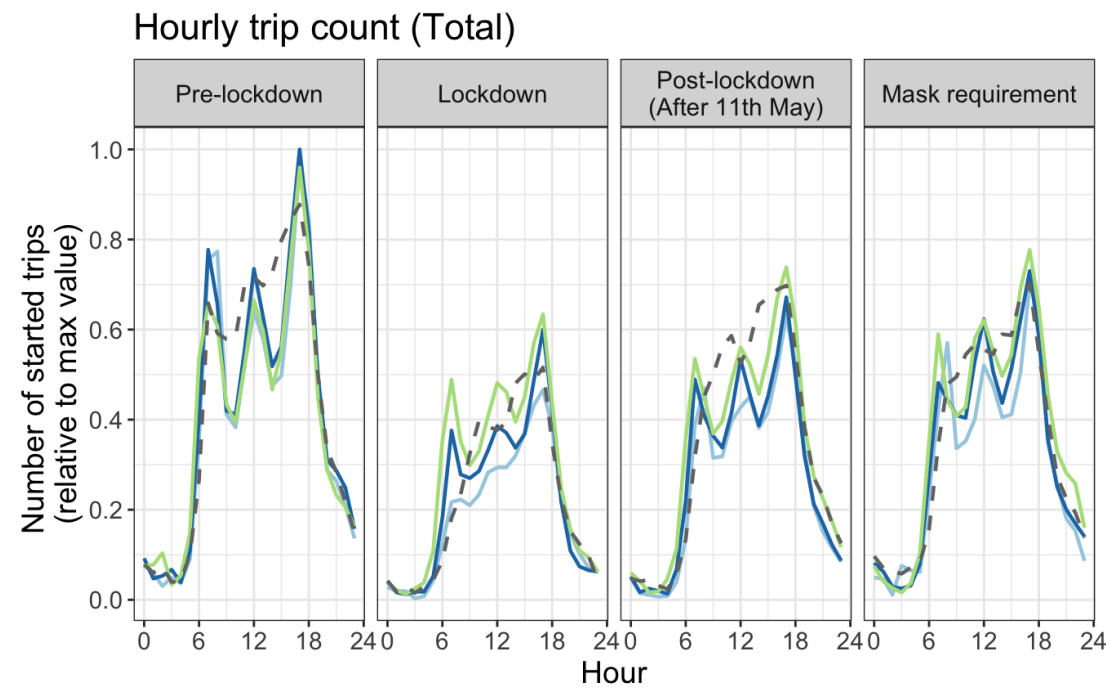

Work location - Home office - Mixture - Work outside home - Non-worker 


\section{Reduction in kilometers travelled by Canton}

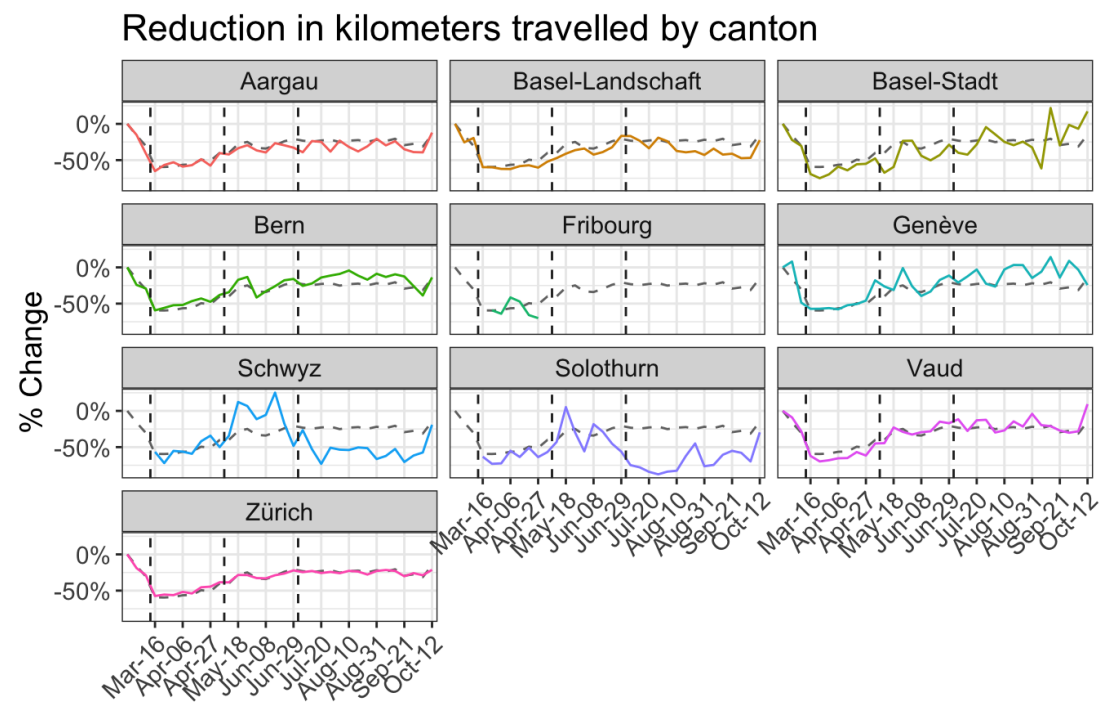

Week

dashed - overall average

\section{Trip duration by transport mode and gender}

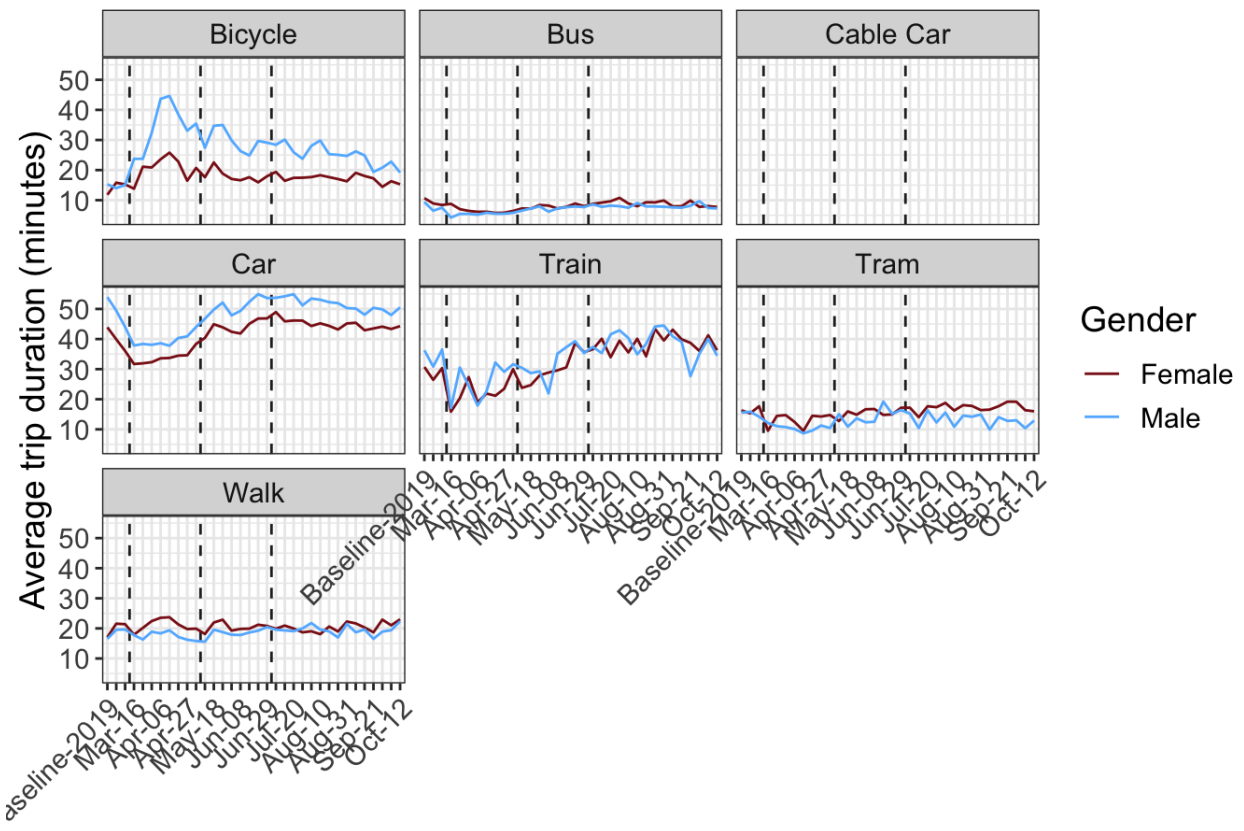

Week 


\section{Average stage length by transport mode $(\mathrm{km})$}

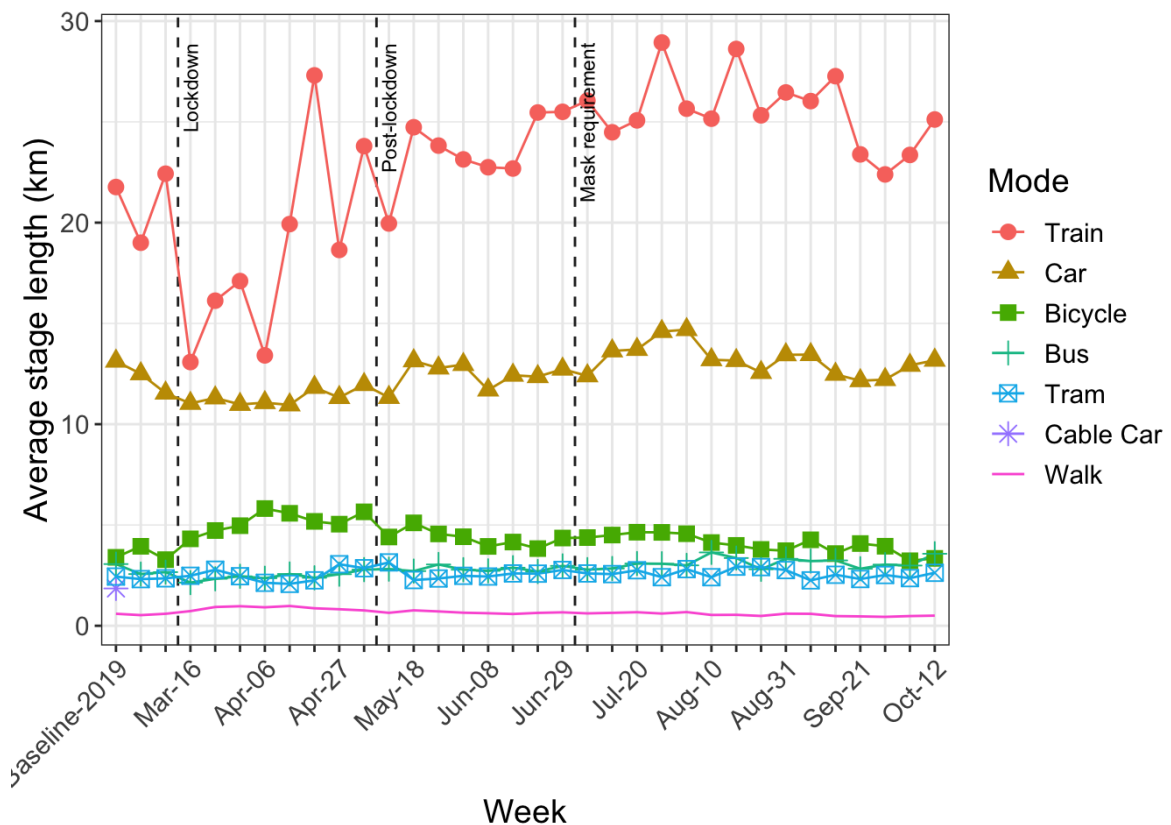

\section{Activity space and daily travel radius}

A commonly used definition of the activity space is the $95 \%$ confidence ellipse of the activity locations, in this case weighted by duration. In the following analysis, the activities at the home location are included, for those that had the app activated on that day. This is an important metric which gives an idea of the area in which travel is being performed. The daily travel radius is also presented.
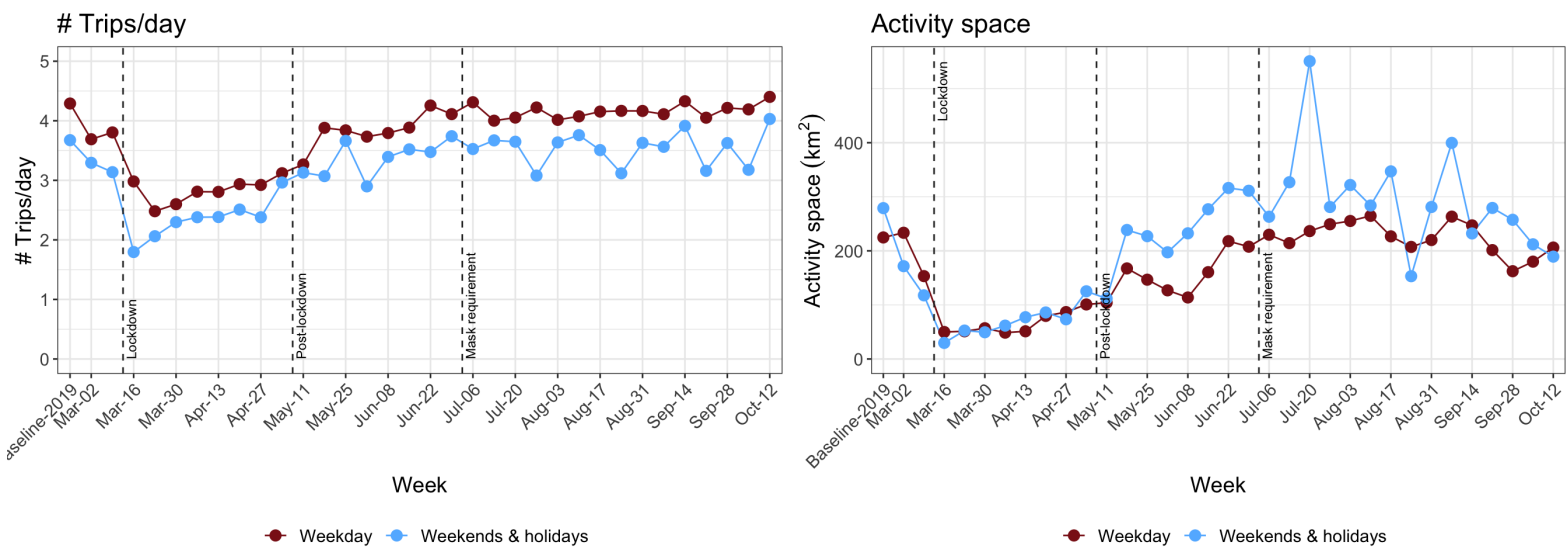

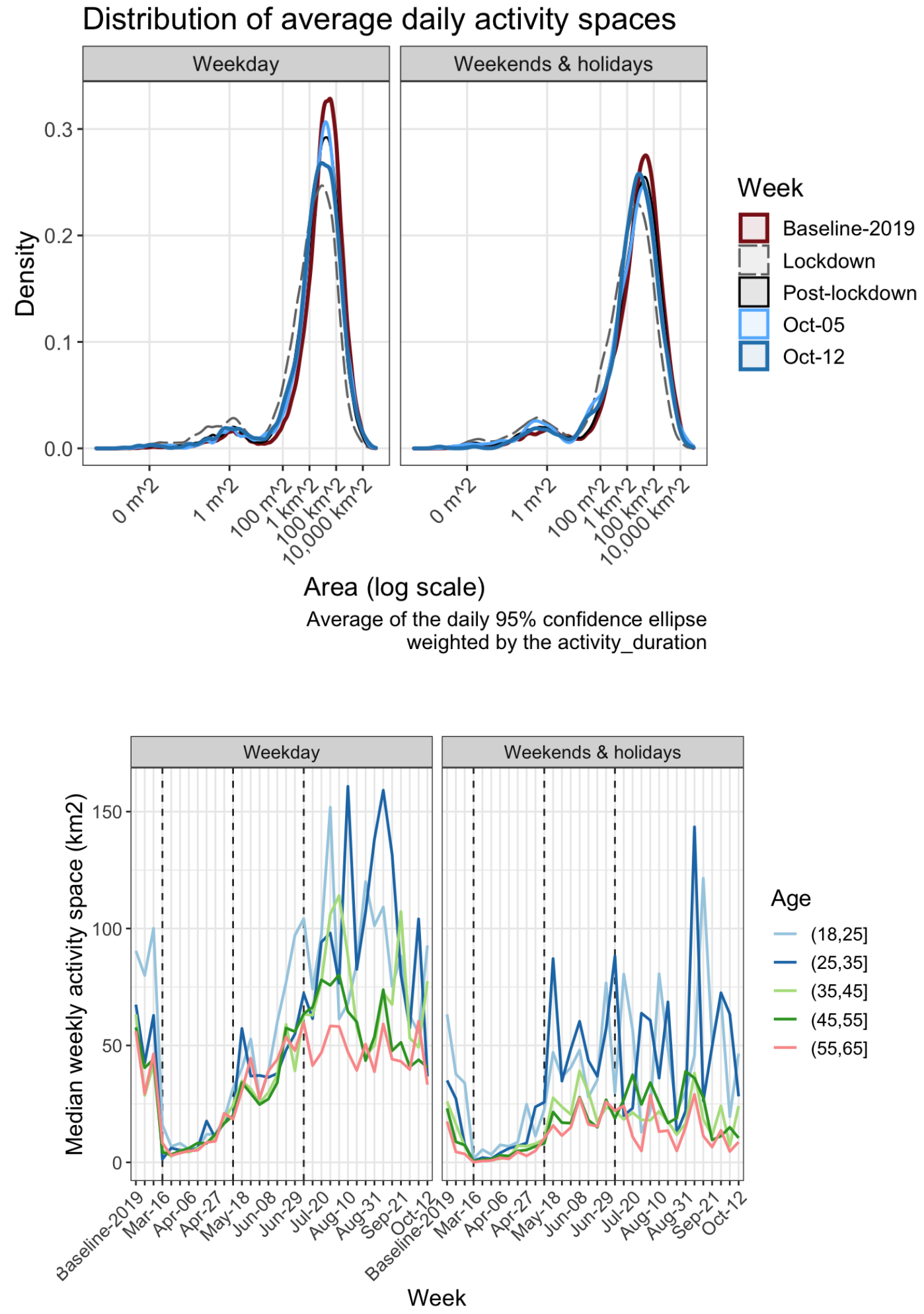


\section{Hourly counts}

The number of trips started per hour. The y axis is normalized by the maximum hourly value in the graph.

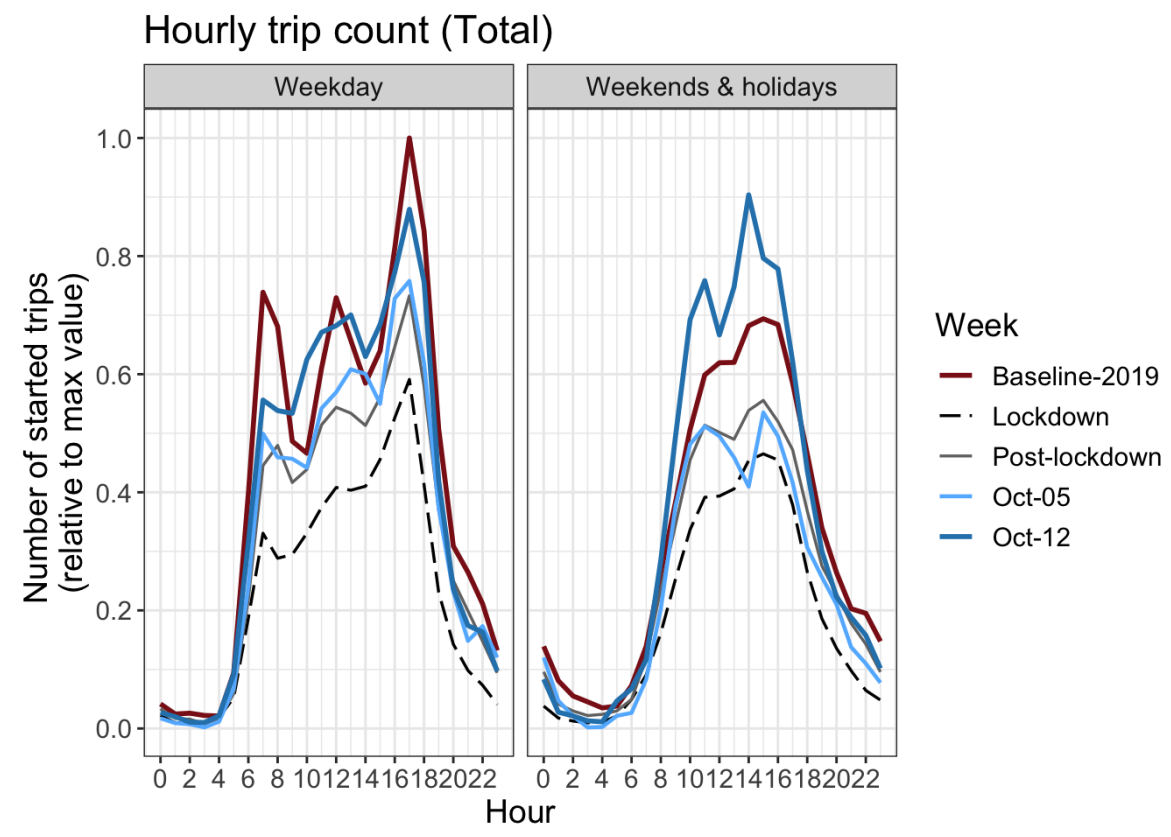

Hourly trip count (Car)

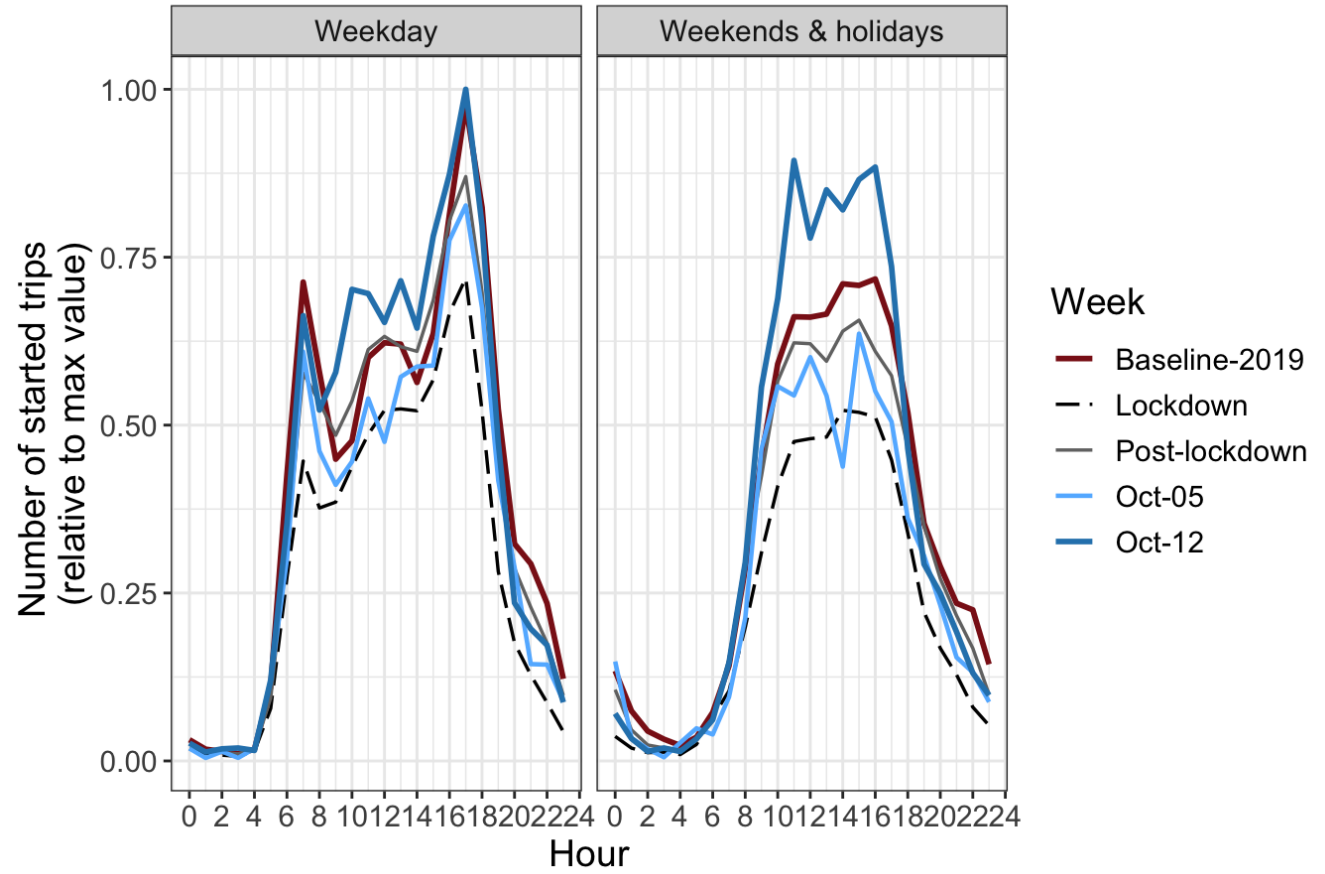




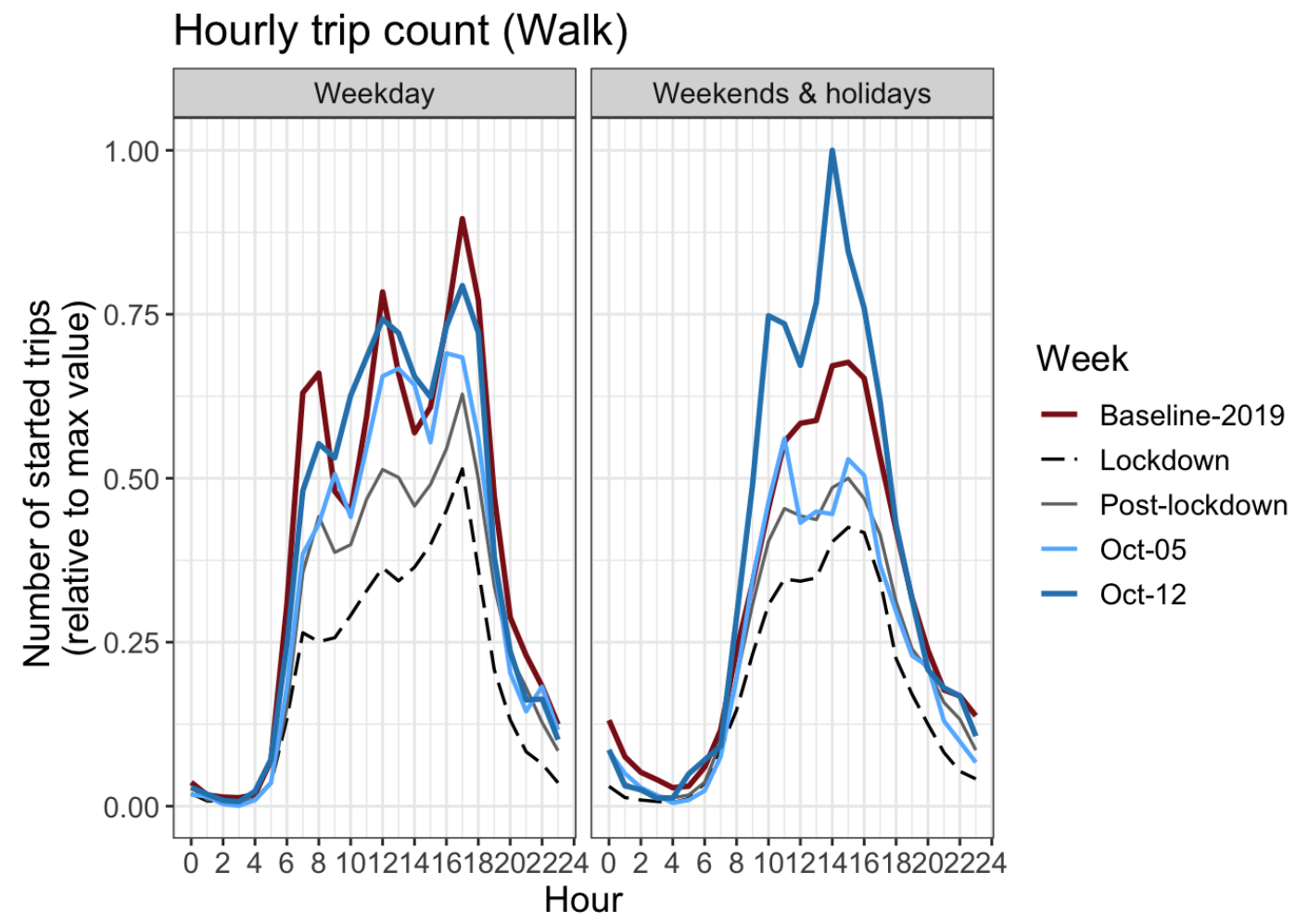

Hourly trip count (Train)

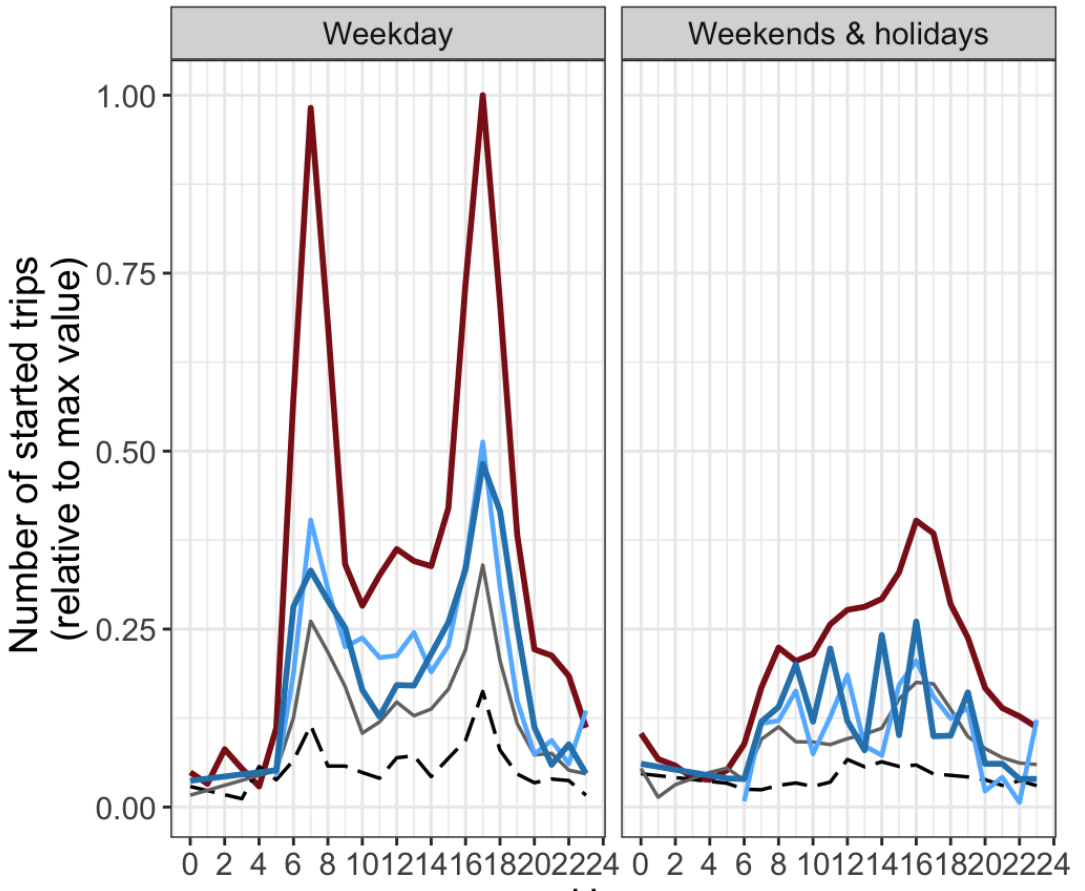

Week

- Baseline-2019

- . Lockdown

- Post-lockdown

- Oct-05

- Oct-12

Hour 


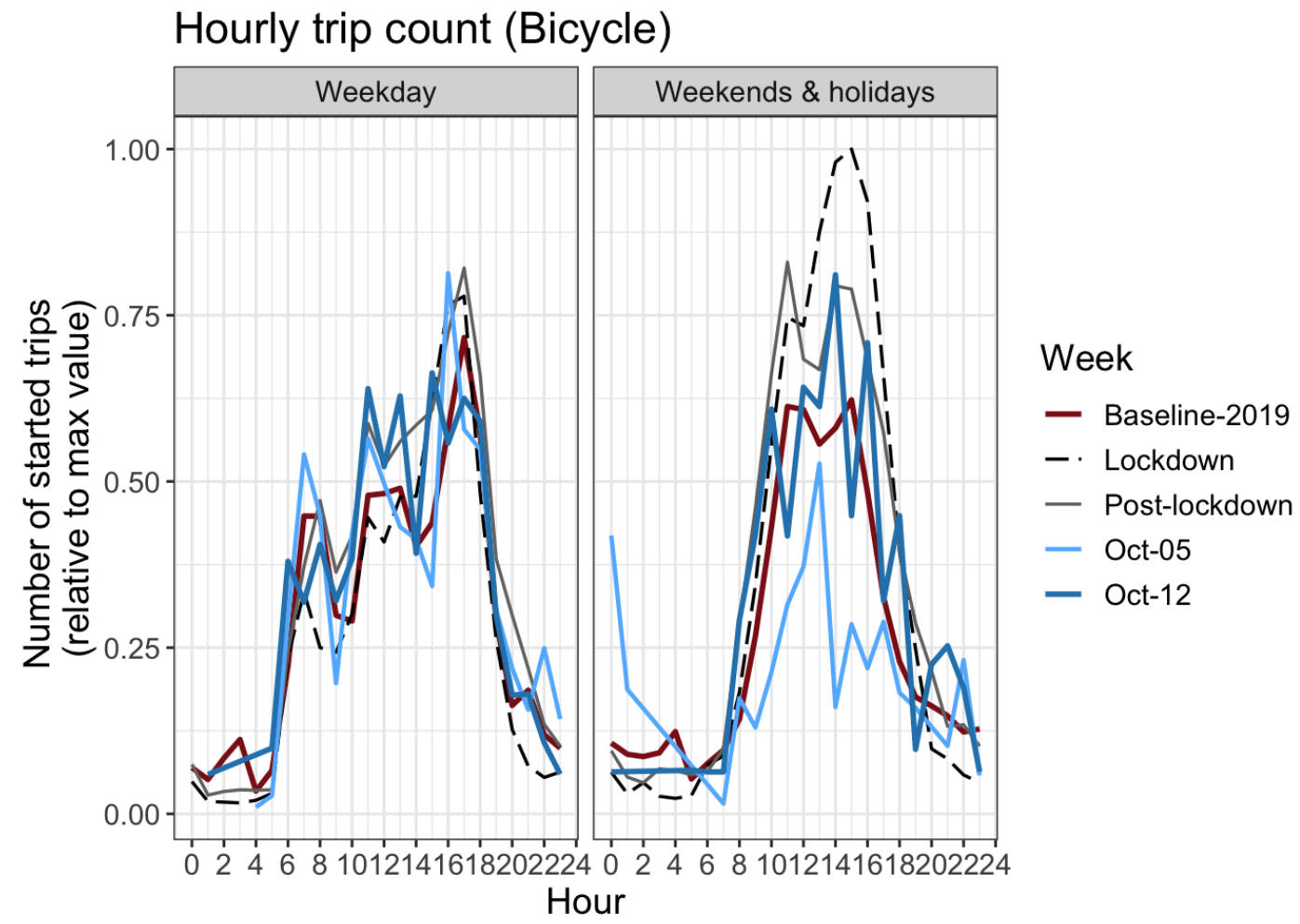

Hourly trip count (Local PT)

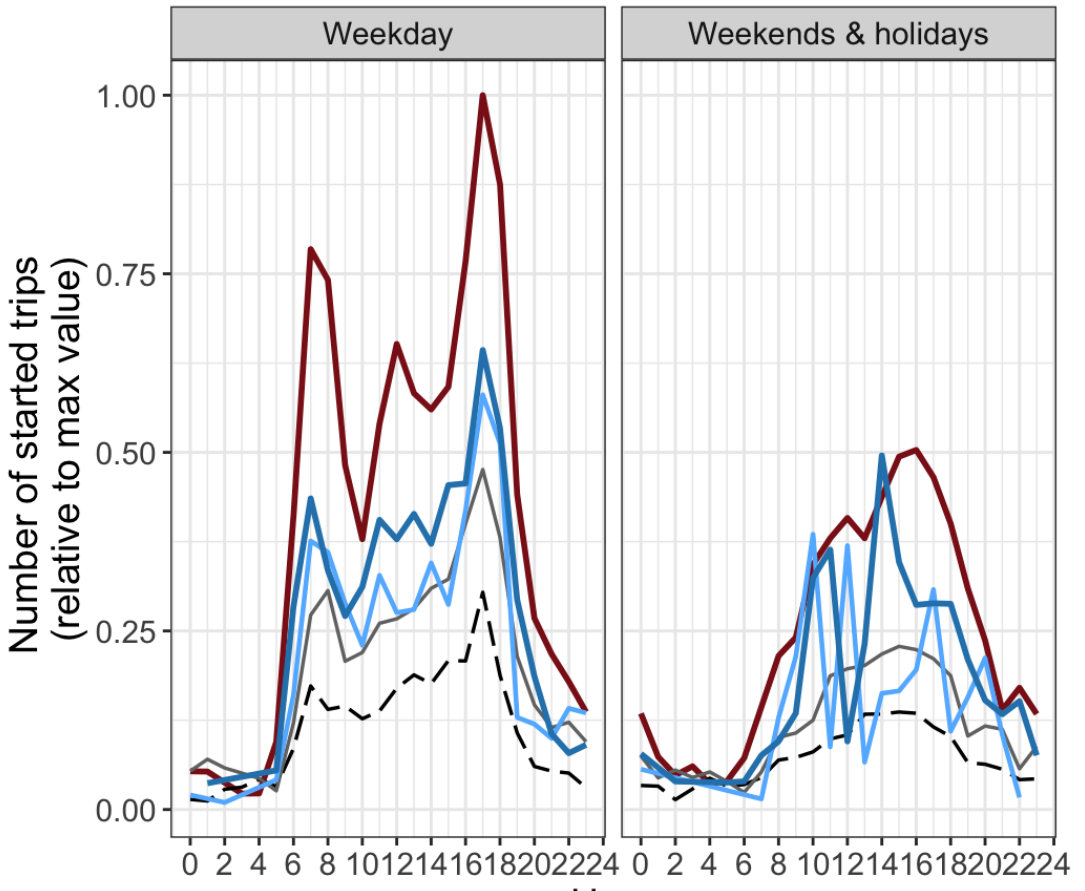

Week

- Baseline-2019

- . Lockdown

- Post-lockdown

- Oct-05

- Oct-12

Hour 


\section{Activity types and zoning}

Around $30 \%$ of activities were voluntarily labelled with their purpose by participants using the app. Work is ongoing to impute the purposes for the rest of the activities. Using simplification of the ARE development zoning classification, the activities are assigned with the closest zone classification within a $100 \mathrm{~m}$ radius. The following graph shows how both the activity duration and the number of activities has changed from the baseline period in 2019 to the COVID-19 period.

Please note that only stationary leisure activities are included, not walking/cycling/hiking/etc.

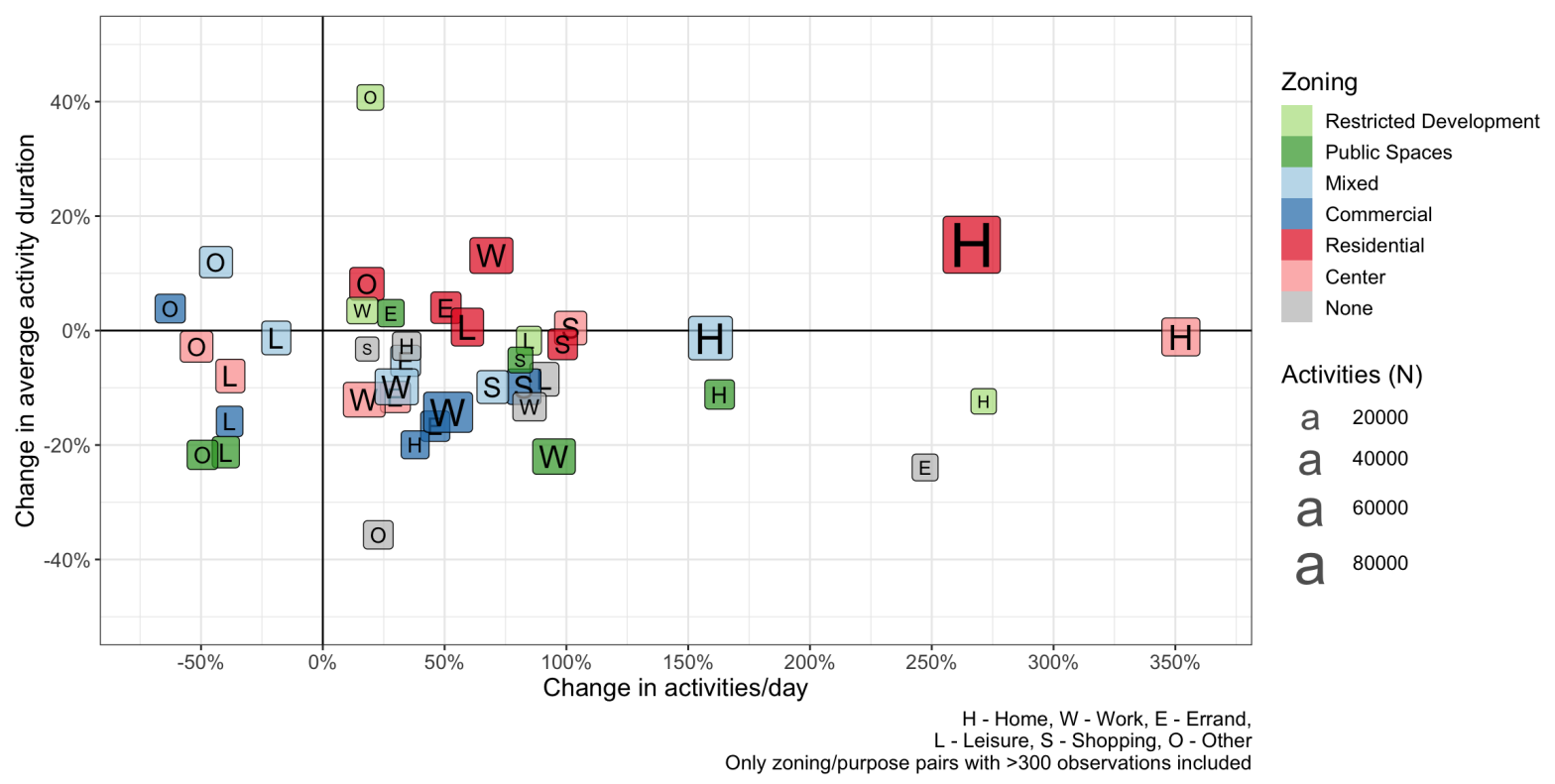




\section{Participation}

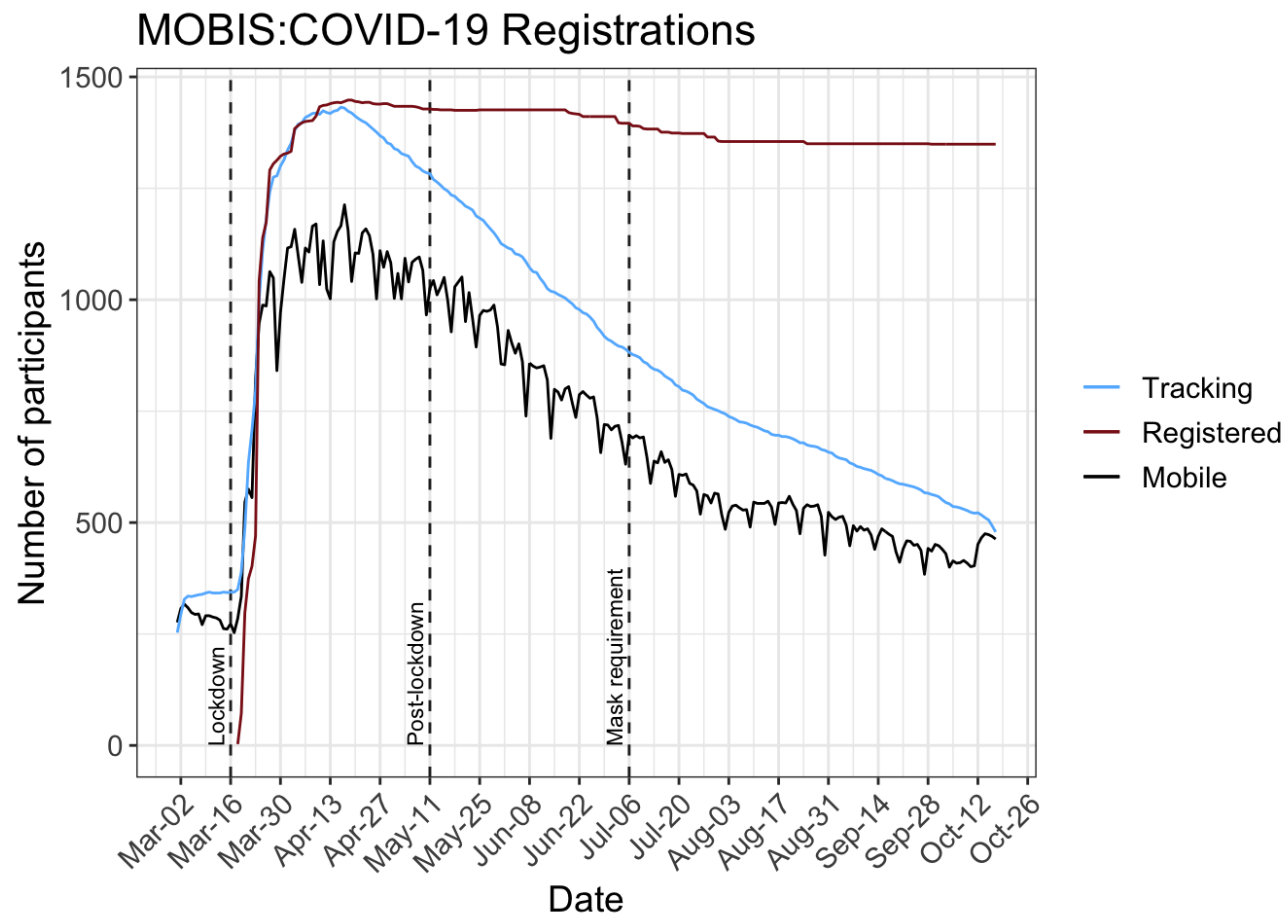

\section{Risk perception}

COVID-19 Survey - October 19, 2020

Risk assessment by gender of participant $(\mathrm{N}=991)$

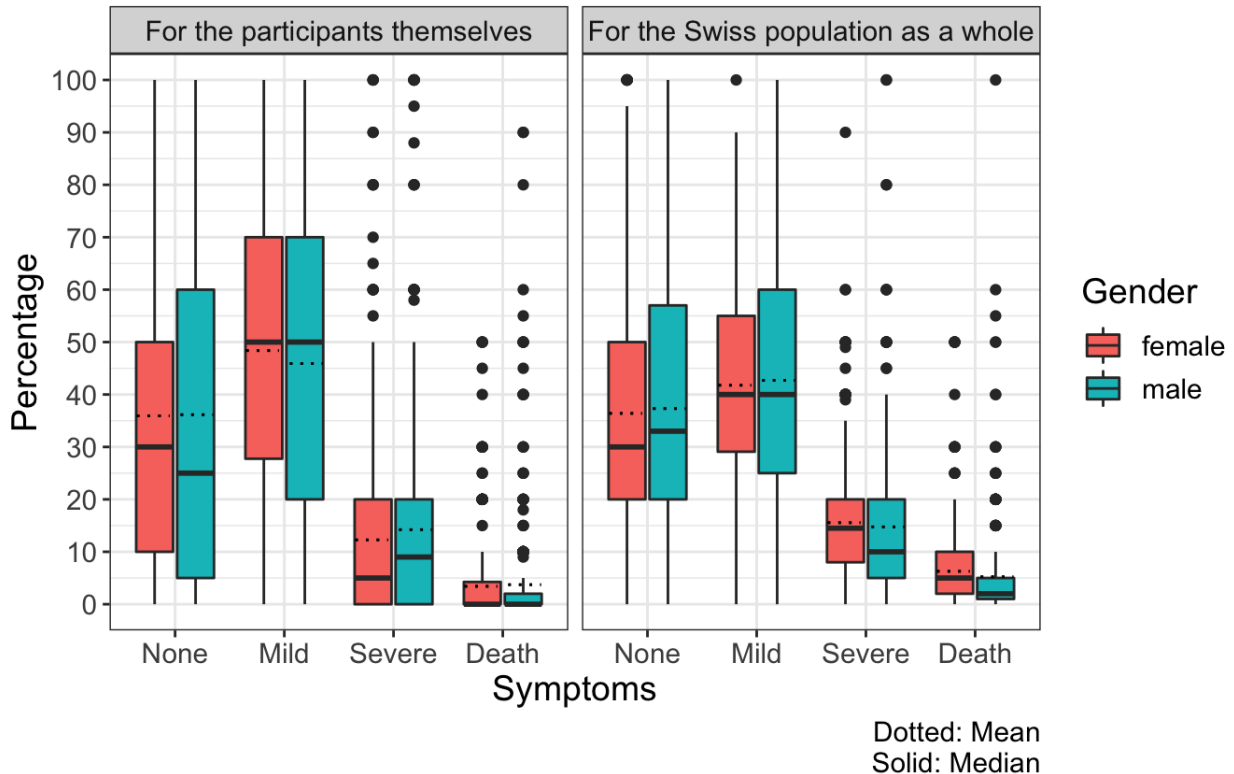


A first analysis from the survey on risk perception in the case of a COVID-19 infection shows that participants evaluate the risks of various outcomes differently for themselves and the Swiss population. The possibility that the participant experiences severe symptoms that require hospitalisation or fatal symptoms is considered somewhat lower by the participants for themselves than for the Swiss population. Both men and women appear to overestimate the probability of death by expecting the "asymptomatic" course to be less likely. While the median values for the various symptom categories do not differ greatly between men and women, the range of values for men is somewhat wider than for women.

\section{Differences in the distributions}

The following charts show the characteristics of the MOBIS:COVID-19 sample compared to the original MOBIS sample. There are some small differences, but generally the samples are consistent. This chart will be extended to compare to the relevant census data.
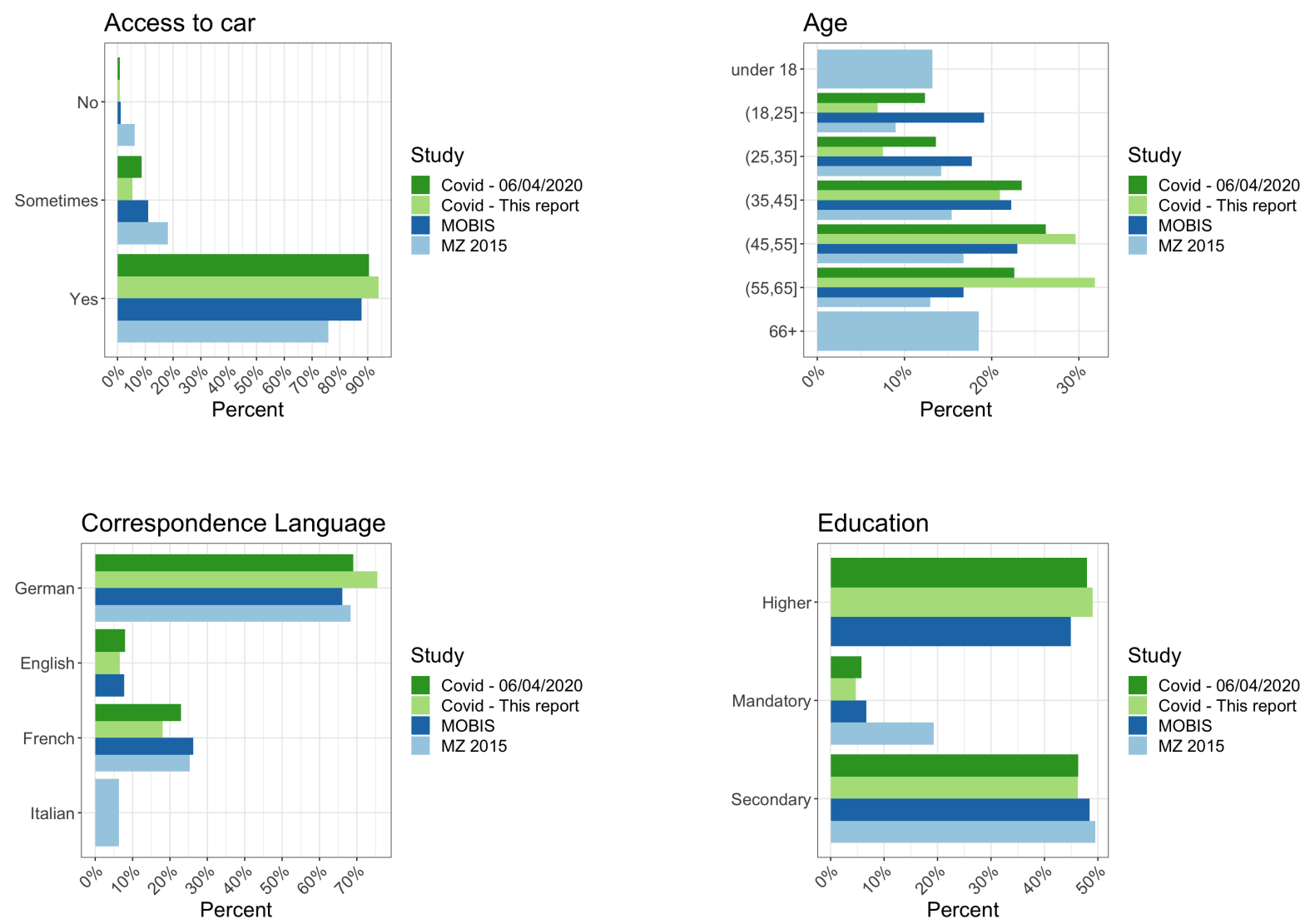

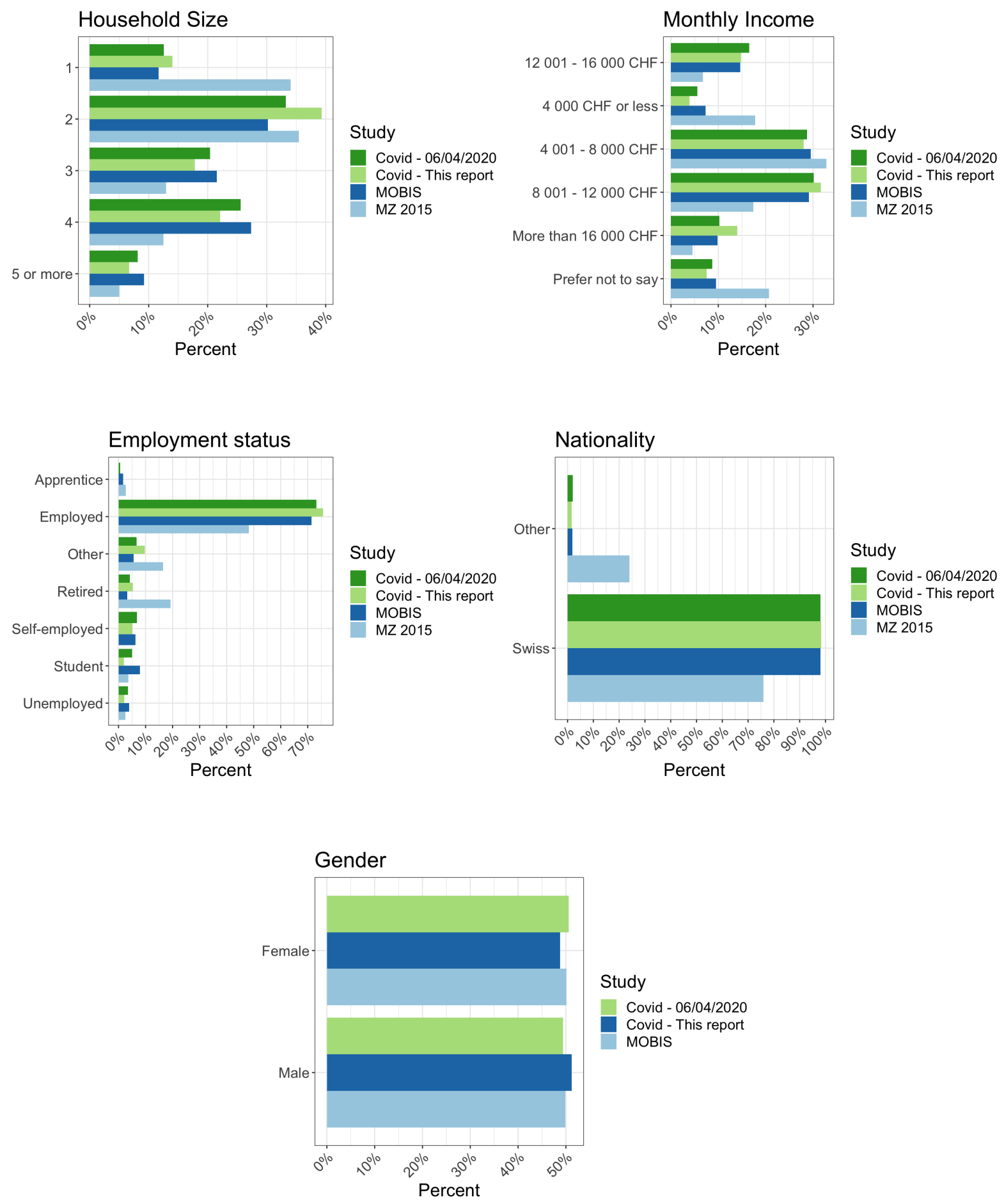
Table 1: Comparison with the last national travel diary Mikrozensus (MZ) 2015

\begin{tabular}{l|r|r|r|r|r|r}
\hline \multirow{2}{*}{} & \multicolumn{4}{|c|}{ Covid } & \multicolumn{2}{c}{ MZ } \\
\cline { 2 - 6 } & $06 / 04 / 2020$ & \multicolumn{2}{c}{ This report } & & \\
\cline { 2 - 6 } Aargau & $\mathrm{N}$ & $\%$ & $\mathrm{~N}$ & $\%$ & $\mathrm{~N}$ & $\%$ \\
\hline Basel-Landschaft & 189 & 11.4 & 58 & 11.5 & 1,940 & 3.4 \\
\hline Basel-Stadt & 40 & 2.4 & 17 & 3.4 & 1,555 & 2.7 \\
\hline Bern & 192 & 11.6 & 59 & 11.7 & 7,244 & 12.7 \\
\hline Fribourg & 8 & 0.5 & - & - & 1,942 & 3.4 \\
\hline Geneva & 128 & 7.7 & 31 & 6.1 & 3,062 & 5.4 \\
\hline Schwyz & 17 & 1.0 & 8 & 1.6 & 1,005 & 1.8 \\
\hline Solothurn & 19 & 1.1 & 7 & 1.4 & 1,813 & 3.2 \\
\hline Vaud & 297 & 17.9 & 67 & 13.2 & 5,303 & 9.3 \\
\hline Zurich & 680 & 41.0 & 224 & 44.3 & 10,410 & 18.2 \\
\hline Other & 4 & 0.2 & 2 & 0.4 & 18,491 & 32.4 \\
\hline
\end{tabular}

\section{Sample weighting}

In order to account for the fluctuating size and composition of the sample, participant weights have been calculated and applied for each week of MOBIS-Covid Study (including the weeks in the baseline period). Hence, the results are corrected for weeks where more participants from a certain demographic group started or stopped tracking. The weighting was performed against the original 21,571 participants who completed the introductory questionnaire in the MOBIS Study using IPF (Iterative Proportional Fitting) using the following variables: age, gender, income, education, mobility tool ownership and accessibility. The weighting of the data did not lead to large changes in the results.

\section{Updated conclusions}

Since commencing in this spring, the MOBIS:COVID-19 tracking study has recorded 628,652 person-trips as of 2020-10-19. It includes two small surveys about the work situation and the health of the participants. A maximum of 1,432 persons participated 
and an average of 883. We use the Catch-my-Day smartphone app, which is based on MotionTag technology. The sample is roughly comparable in socio-demographics to the latest federal 2015 Mikrozensus, but for a bias towards higher income season-ticket owning better educated males. The denser parts of the German and French speaking parts of the country are also overrepresented in our sample. The conclusions are based on weighted results which ensure that the sample matches the representative sample of around 20,000 invited persons in the original MOBIS study. The weights were calculated based on age, sex, education, income, mobility tool ownership and the accessibility level of a person's home location.

Our study is not the only source for Switzerland which traced the impact of the pandemic and of the measures implemented to contain it. The Intervista panel has been funded by different federal offices during these months. The available Google data has the advantage of being available worldwide, but only for high-level geographies and without any sociodemographics. We can draw on a more detailed self-description of the participants using their socio-demographics and their attitudes.

The central observations focus on the ongoing acceptance of "Working from Home (WFH)" or in German "Home-office" and the modal shift in the recovery of the trip volumes and in the miles driven. Equally important is the comparatively much lower social selectivity of the impacts in Switzerland.

The share of active, i.e. mobile, days shows the anticipation of the lockdown and then the recovery and stabilization to about $80 \%$ in August. This is substantially below the $90+\%$ share, which one can expect (Madre et al., 2007). This lower share must be a mixture of WFH, persons furloughed or newly unemployed. We don't yet know how firms will handle WFH in the coming weeks. There have been prominent announcements of firms not calling staff back to the office, e.g. Facebook, twitter, PSA, but equally prominent ones calling their employees back, e.g, Stadler. If mobilized, this suppressed demand would meet a road system where the average speeds are already at pre pandemic levels conditions which could lead to increased congestion.

The population has shifted away from space-efficient large vehicles, as busses, trams and trains remain unpopular. Usage is down between $40 \%$ to $60 \%$ of the 2019 ridership after a near complete avoidance in the first weeks after the lockdown. On average, car travel has fully recovered. Equally, walking has fully recovered. It is worth noting that demand never dropped in the same way as for the other modes. The surprise was, and still is the increased bicycle usage backed up by a boom in cycle acquisition. While 
the increase seemed initially to be mostly a fitness, leisure boom, the recent imputation of the trip purposes has shown that the cycle gained for all purposes with leisure and shopping the most prominent ones. Commuting to work by bike also increased, but not as strongly (about $40 \%$ versus $60-80 \%$ for the other purposes). It is interesting to see how the increasing competition for road space since the end of the lockdown has dampened cycling. The new freedom in time allocation is visible in the cycling for leisure during the day.

Finally, the experience of the COVID19 period confirms the results of earlier telecommuting experiments (Pendyala et al., 1991). They had shown that the total mileage is not reduced, as the persons used the liberated time for other travel. Here, the Kurzarbeiter (furloughed) track the trends and actually travel a bit more than the other workers. Those working from home do travel less than those who have to go to their workplaces, but the difference is not nearly as large as one would expect.

\section{References}

Madre, J.-L., K.W. Axhausen and W. Brög (2007) Immobility in travel diary surveys, Transportation, 34 (1) 107-128.

Pendyala, R.M., Goulias, K.G. and R. Kitamura (1991) Impact of telecommuting on spatial and temporal patterns of household travel, Transportation, 18 (4) 383-409.

This work is licensed under a Creative Commons "AttributionNonCommercial-ShareAlike 4.0 International" license. 